\title{
Selective Adsorption and Electrocatalysis of Polysulfides through Hexatomic Nickel Clusters Embedded in N-Doped Graphene toward High-Performance Li-S Batteries
}

\author{
Jiapeng Ji, ${ }^{1}$ Ying Sha, ${ }^{1}$ Zeheng Li, ${ }^{1}$ Xuehui Gao, ${ }^{1}$ Teng Zhang, ${ }^{2}$ Shiyu Zhou, ${ }^{1}$ Tong Qiu, \\ Shaodong Zhou, ${ }^{1}$ Liang Zhang, ${ }^{3}$ Min Ling ${ }^{1},{ }^{1}$ Yanglong Hou $\left(\mathbb{0},{ }^{2}\right.$ and Chengdu Liang ${ }^{1}$ \\ ${ }^{1}$ Zhejiang Provincial Key Laboratory of Advanced Chemical Engineering Manufacture Technology, College of Chemical and \\ Biological Engineering, Zhejiang University, Hangzhou 310027, China \\ ${ }^{2}$ Beijing Key Laboratory for Magnetoelectric Materials and Devices, Beijing Innovation Center for Engineering Science and Advanced \\ Technology (BIC-ESAT), Department of Materials Science and Engineering, College of Engineering, Peking University, \\ Beijing 100871, China \\ ${ }^{3}$ Institute of Functional Nano \& Soft Materials (FUNSOM), Jiangsu Key Laboratory for Carbon-Based Functional Materials \\ \& Devices, Joint International Research Laboratory of Carbon-Based Functional Materials and Devices, Soochow University, \\ Suzhou, 215123 Jiangsu, China
}

Correspondence should be addressed to Min Ling; minling@zju.edu.cn and Yanglong Hou; hou@pku.edu.cn

Received 21 March 2020; Accepted 2 June 2020; Published 26 June 2020

Copyright (c) 2020 Jiapeng Ji et al. Exclusive Licensee Science and Technology Review Publishing House. Distributed under a Creative Commons Attribution License (CC BY 4.0).

\begin{abstract}
The shuttle effect hinders the practical application of lithium-sulfur (Li-S) batteries due to the poor affinity between a substrate and $\mathrm{Li}$ polysulfides (LiPSs) and the sluggish transition of soluble LiPSs to insoluble $\mathrm{Li}_{2} \mathrm{~S}$ or elemental $\mathrm{S}$. Here, we report that $\mathrm{Ni}$ hexatomic clusters embedded in a nitrogen-doped three-dimensional (3D) graphene framework (Ni-N/G) possess stronger interaction with soluble polysulfides than that with insoluble polysulfides. The synthetic electrocatalyst deployed in the sulfur cathode plays a multifunctional role: (i) selectively adsorbing the polysulfides dissolved in the electrolyte, (ii) expediting the sluggish liquid-solid phase transformations at the active sites as electrocatalysts, and (iii) accelerating the kinetics of the electrochemical reaction of multielectron sulfur, thereby inhibiting the dissolution of LiPSs. The constructed S@Ni-N/G cathode delivers an areal capacity of $9.43 \mathrm{mAh} \mathrm{cm}^{-2}$ at $0.1 \mathrm{C}$ at $\mathrm{S}$ loading of $6.8 \mathrm{mg} \mathrm{cm}^{-2}$, and it exhibits a gravimetric capacity of $1104 \mathrm{mAh} \mathrm{g}^{-1}$ with a capacity fading rate of $0.045 \%$ per cycle over 50 cycles at $0.2 \mathrm{C}$ at $\mathrm{S}$ loading of $2.0 \mathrm{mg} \mathrm{cm}^{-2}$. This work opens a rational approach to achieve the selective adsorption and expediting of polysulfide transition for the performance enhancement of Li-S batteries.
\end{abstract}

\section{Introduction}

In imminent pursuit of next-generation electrical energy storage (EES) technologies, lithium-sulfur (Li-S) batteries have attracted enormous research interests due to the high sulfurspecific capacity of $1675 \mathrm{mAh} \mathrm{g}^{-1}$ and the earth-abundant sulfur sources [1-4]. However, the practical application of Li-S batteries is hindered by multiple challenges, i.e., the insulation of $\mathrm{S}$ and its discharge products $\left(\mathrm{Li}_{2} \mathrm{~S}_{2} / \mathrm{Li}_{2} \mathrm{~S}\right)$, the large volume fluctuation, and the flagrant dissolution of $\mathrm{Li}_{2} \mathrm{~S}_{x}(4 \leq x \leq 8)$ into the electrolyte during charge/discharge cycles [5]. One common countermeasure to address the shuttling effects is to adsorb Li polysulfides (LiPSs) through the porous carbon hosts [6], binder [7], and membrane [8,9]. Another recently emerging alternative is the use of electrocatalysts in the cathode to accelerate the conversion of soluble LiPSs to insoluble end products (sulfur in the charge reaction and $\mathrm{Li}_{2} \mathrm{~S}$ in the discharge reaction), thereby reducing the polysulfide presence in the electrolyte [10-12]. Similar to adsorbent materials, an excellent electrocatalyst in the sulfur cathode must also have strong interaction with LiPSs, together with good electronic conductivity and electrochemical stability simultaneously.

Nonetheless, most adsorbent materials or electrocatalysts reported to date have not paid close attention to selective 
adsorption of specific polysulfide. Specifically, adsorption sites have strong interaction with both soluble polysulfide $\left(\mathrm{Li}_{2} \mathrm{~S}_{x}, 4 \leq x \leq 8\right)$ and insoluble polysulfide $\left(\mathrm{Li}_{2} \mathrm{~S}_{2} / \mathrm{Li}_{2} \mathrm{~S}\right)$, which cannot preferentially adsorb the former [13-17]. Moreover, the entropy-reduced liquid-solid phase transformations of soluble LiPSs and insoluble LiPSs at the catalytic sites have to overcome certain energy barriers [12]. As a result, active sites are mainly occupied by insoluble polysulfide with stronger interaction and the catalytic activity gradually declines. We propose here to exploit an electrocatalyst, which not only has stronger interaction with soluble polysulfides than that with insoluble polysulfides but also can selectively collect the polysulfide dissolved in the electrolyte and constantly "kick off" the immobilized insoluble polysulfide at the catalytic site, thus accelerating the kinetics of the electrochemical reaction of multielectron sulfur and reducing the dissolution of $\mathrm{Li}_{2} \mathrm{~S}_{x}(4 \leq x \leq 8)$ into the electrolyte.

Here, in order to confirm our concept, we intentionally prepared an $\mathrm{N}$-doped 3D graphene framework embedded with $\mathrm{Ni}$ atomic clusters (Ni-N/G) as a sulfur cathode host material for Li-S batteries. The morphology and coordination configuration of Ni clusters at the atomic level were identified by high-angle annular dark-field imaging-scanning transmission electron microscopy (HAADF-STEM) and synchrotron $\mathrm{X}$-ray absorption spectroscopy. Density functional theory (DFT) calculation results further revealed that the atomicscale $\mathrm{Ni}_{6}-\mathrm{N}-\mathrm{C}$ configuration possesses distinctive binding energies of LiPS species, which effectively inhibit the dissolution and enhance the conversion of LiPSs. Along with high electrical conductivity, hierarchically porous 3D structure, and large specific surface, the synthetic electrocatalyst exhibits impressive electrochemical performances in Li-S batteries. This work illustrates the important role of selective adsorption in inhibiting dissolution and enhancing the redox kinetics of polysulfides.

\section{Results and Discussion}

2.1. Synthesis and Characterization. The synthesis procedure of Ni-N/G is schematically illustrated in Figure 1(a) [18-20]. Firstly, active Ni species were introduced during the growth of a zinc-based zeolite imidazole framework (ZIF-8) by simultaneously adding $\mathrm{Ni}$ and $\mathrm{Zn}$ ions with 2-methylimidazole in methanol at $60^{\circ} \mathrm{C}$. Tetrahedral $\mathrm{Ni}-\mathrm{N}_{4}$ structures are likely existent in the precursors of $\mathrm{Zn}-\mathrm{N}_{4}$ complexes, as there is no change in the identical XRD pattern obtained before and after doping (Figure 1(b)) [20]. Subsequently, the precursors were carbonized and reconstructed with sodium gluconate carbon (GS) in a nitrogen atmosphere. During the heating process, graphene nanosheets (GNs) were formed through thermal cyclodehydration and in-plane carbon reconstruction of sodium gluconate carbon in molten $\mathrm{Na}_{2} \mathrm{CO}_{3}$ media. Once the temperature exceeded $907^{\circ} \mathrm{C}, \mathrm{Zn}$ in $\mathrm{ZIFs}$ was violently evaporated, resulting in porous carbon structures, and $\mathrm{Ni}$ doped ZIFs were broken into random cyclized carbonaceous radicals modified with heteroatom $\mathrm{Ni}$ and $\mathrm{N}$ [19]. Finally, $\mathrm{Ni}$ species were anchored by nitrogen atoms and in situ atomically dispersed in a hierarchical graphene framework through carbothermal reduction.
The morphology and structures of samples were characterized by scanning electron microscopy (SEM) and $\mathrm{X}$-ray diffraction (XRD) analysis. SEM images confirm that Ni-N/G has porous sphere framework morphology similar to the plant cell wall (Figure 1(c)), whereas the control samples without the introduction of $\mathrm{Ni}$, gs, or Ni-ZIFs (N/G, Ni-N/C, and GNs) have entirely different morphologies (Figure S1). Transmission electron microscopy (TEM) images further demonstrate the 3D hierarchically porous framework consisting of abundant nanopores $(\sim 50 \mathrm{~nm}$ in diameter) interconnected with each other by graphene (Figure $1(\mathrm{~d})$ ). No Ni-derived nanoparticles are detected in high-resolution TEM (HRTEM) except for the lattice stripes of graphene (Figure S2). The N/G composite and GNs along with wrinkled surfaces also exhibit a characteristic graphene diffraction ring, consistent with the former research (Figures S3-S4) [21]. The size of independent carbonized NiZIF particles (Ni-N/C) is around $250 \mathrm{~nm}$ (Figure S5). The structure of Ni-N/G at the atomic scale is further revealed by high-angle annular dark-field (HAADF) imaging with aberration-corrected scanning TEM (STEM). As shown in Figure 1(e), numerous individual bright spots can be seen, which are attributed to atomically dispersed $\mathrm{Ni}$ on the surface of Ni-N/G [22]. The distinct spatial distributions of $\mathrm{Ni}, \mathrm{C}, \mathrm{N}$, and $\mathrm{O}$ elements for these four samples are confirmed by the energy-dispersive X-ray spectroscopy (EDX) elemental mapping images (Figures $1(\mathrm{f})$ and $1(\mathrm{~g})$ and Figures S6-S9, Table S1), suggesting the uniform distribution of nickel and nitrogen elements.

$\mathrm{XRD}$ patterns confirm the formation of graphene carbon in Ni-N/G during pyrolysis. As shown in Figure S10, a broad peak centered at $25.3^{\circ}$ is observed in Ni-N/G, corresponding to the characteristic peaks of graphene and implying that the stacking of graphene is not well ordered [19]. The same phenomena are observed in another two contrast samples, namely, N/G and GNs. However, when sodium gluconate was removed from the reaction system, i.e., Ni-N/C, the graphene peak is accompanied by the emergence of a new graphite peak (002) at $26.2^{\circ}$. The graphitic nature of Ni-N/G, N/G, Ni-N/C, and GNs were further corroborated by Raman spectra. As shown in Figure 2(a), the well-resolved D $\left(1344 \mathrm{~cm}^{-1}\right), \mathrm{G}$ $\left(1577 \mathrm{~cm}^{-1}\right)$, and $2 \mathrm{D}\left(2689 \mathrm{~cm}^{-1}\right)$ bands are observed in $\mathrm{Ni}$ N/G, N/G, and GN samples, whereas blocky Ni-N/C exhibits no $2 \mathrm{D}$ band. These results are consistent with those of morphology characterization, indicating that the crisscrossed $3 \mathrm{D}$ graphene framework is derived from carbonization and reconstruction of GS. By comparing the $I_{\mathrm{D}} / I_{\mathrm{G}}$ values of $\mathrm{Ni}$ $\mathrm{N} / \mathrm{G}$ and $\mathrm{N} / \mathrm{G}$, it is inferred that Ni doping may induce more defects on the graphene surface [20]. The nitrogen adsorption-desorption isotherm and corresponding pore size distributions indicate that $\mathrm{Ni}-\mathrm{N} / \mathrm{G}$ possesses an ultrahigh Brunauer-Emmett-Teller (BET) surface area of $919.9 \mathrm{~m}^{2} \mathrm{~g}^{-1}$, a mesoporous size distribution centered at $\sim 3.86 \mathrm{~nm}$, and a total pore volume of $0.948 \mathrm{~cm}^{3} \mathrm{~g}^{-1}$ (Figures 2(b) and Figure S11, Table S2). Due to the huge specific surface area and pore volume, 71.44 to $75.26 \mathrm{wt} \%$ of molten $\mathrm{S}_{8}$ was filled into Ni$\mathrm{N} / \mathrm{G}$ and the control samples in a short time, which is confirmed by TGA curves in Figure S12. 


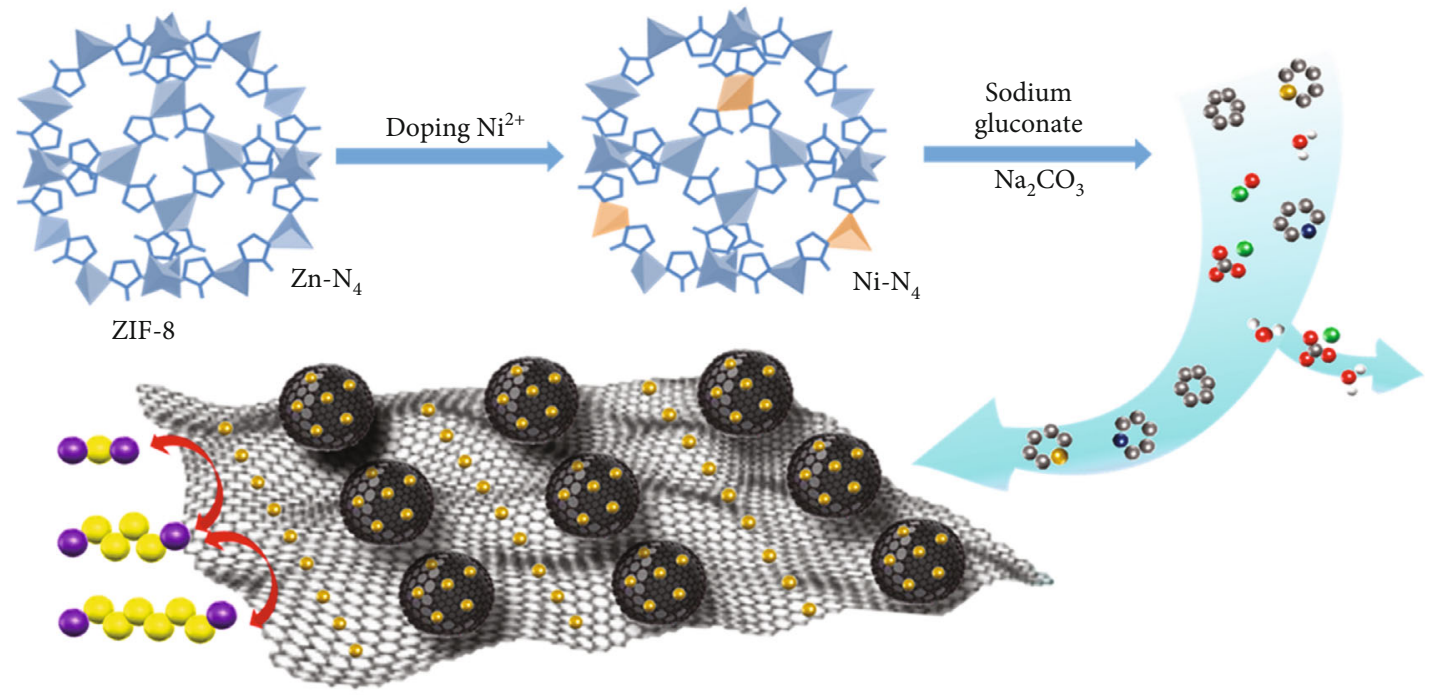
- $\mathrm{H}$
- $\mathrm{N}$
S $\mathrm{S}$
- $\mathrm{Na}$

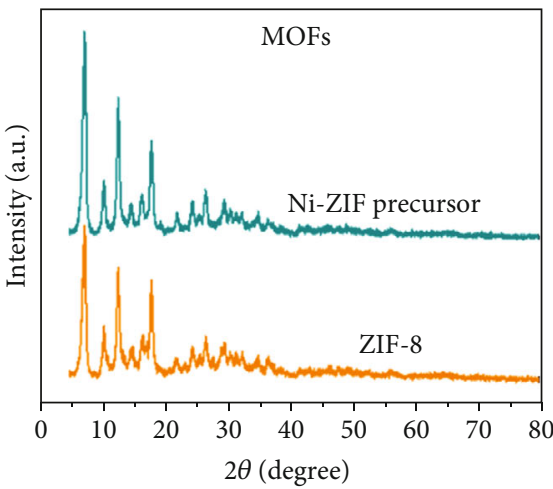

(b)

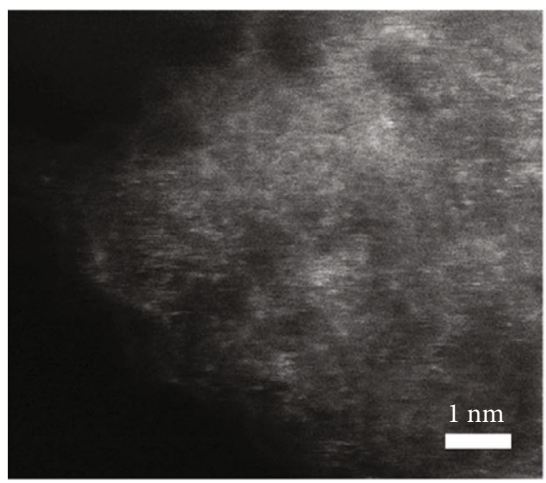

(e)

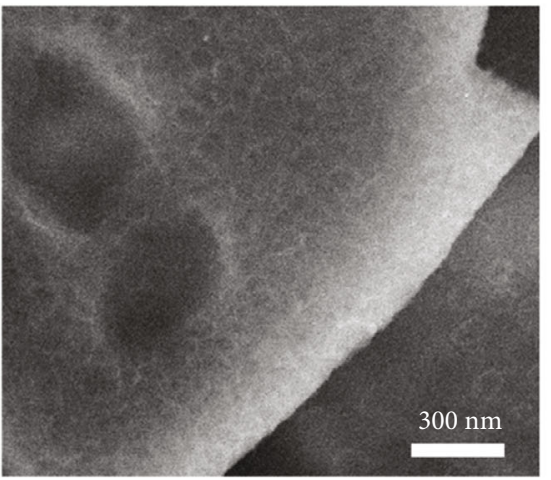

(c)

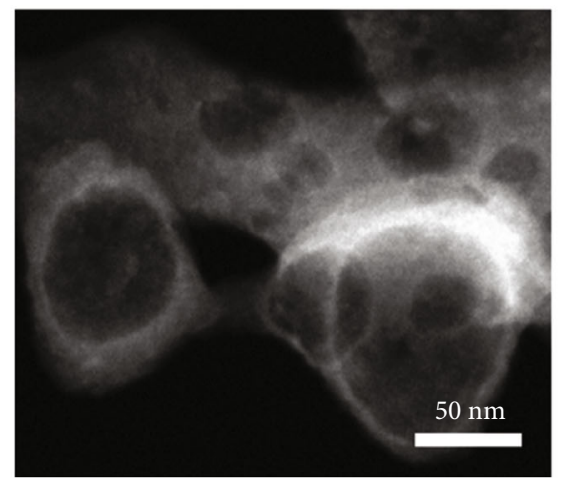

(f)

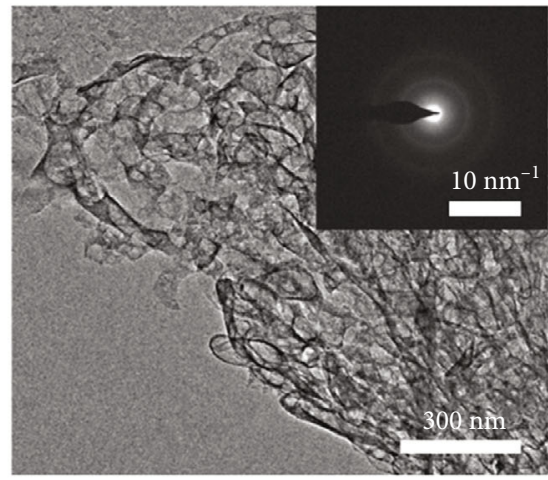

(d)
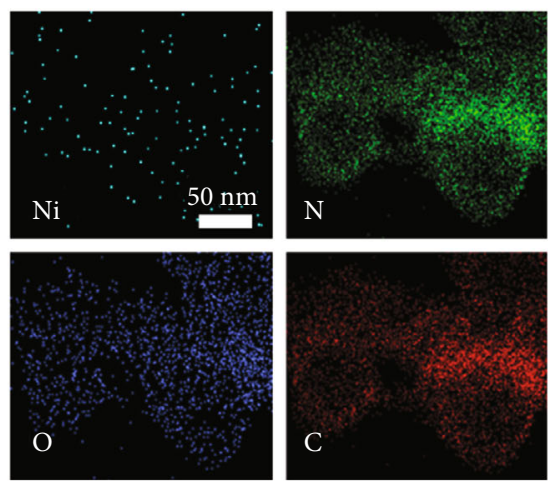

(g)

Figure 1: Synthesis and morphological characterization of the Ni-N/G. (a) Schematic illustration of the synthesis of the 3D graphene framework decorated with nickel atomic clusters (Ni-N/G). (b) XRD patterns of ZIF-8 precursors and Ni-doped ZIF-8 precursors. Representative electron microscopy images. (c) SEM, (d) TEM (inset, corresponding SAEDP), (e) HADDF-STEM, and (f) STEM images of the Ni-N/G sample and (g) corresponding EDX maps (colours) of an individual element. 

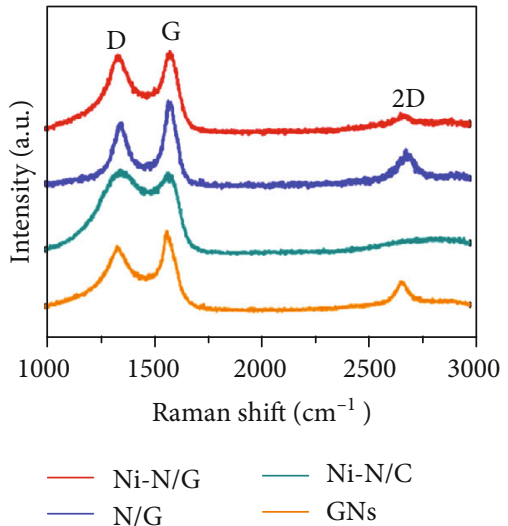

(a)

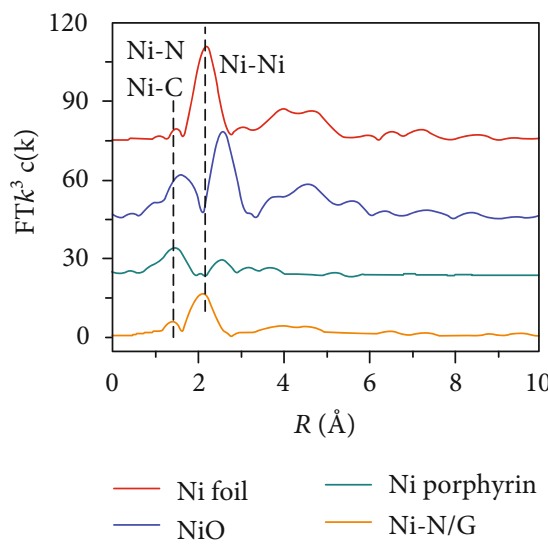

(d)

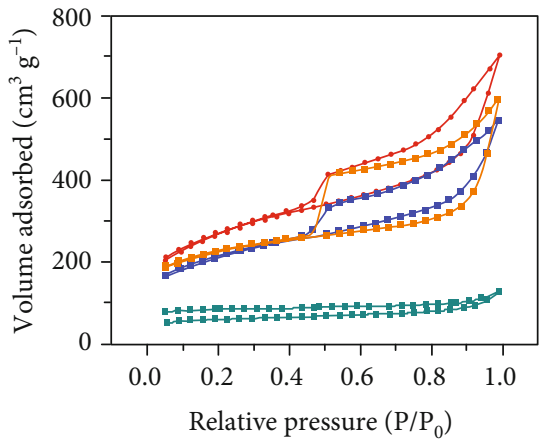

$\rightarrow \mathrm{Ni}-\mathrm{N} / \mathrm{G} \rightarrow \mathrm{Ni-N} / \mathrm{C}$

(b)

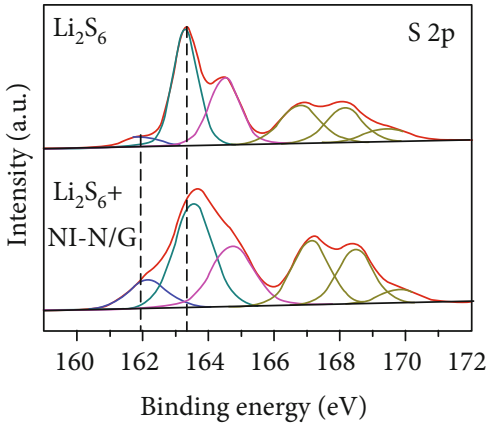

$-\mathrm{S}^{0} \mathrm{~B} 2 \mathrm{P}_{3 / 2} \quad \mathrm{~S} 2 \mathrm{P}_{1 / 2}$

$-\mathrm{S}^{-1} \mathrm{~B} 2 \mathrm{P}_{3 / 2} \longrightarrow$ Sulfate

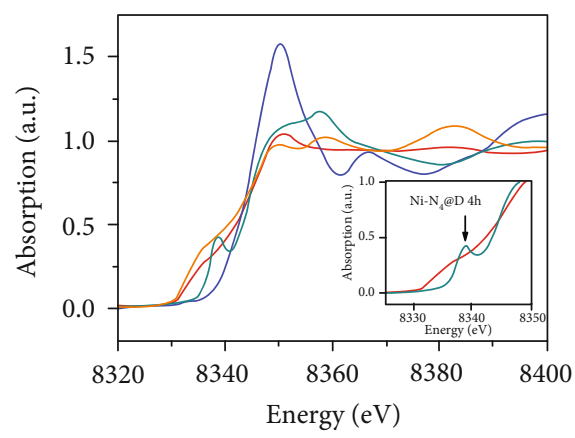

- Ni-N/G - Ni porphyrin

$-\mathrm{NiO}$

(c)

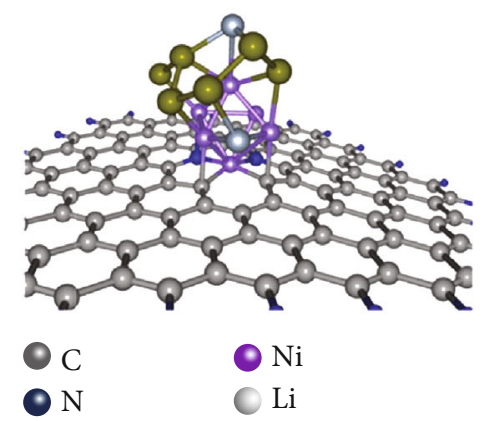

(f)

(e)

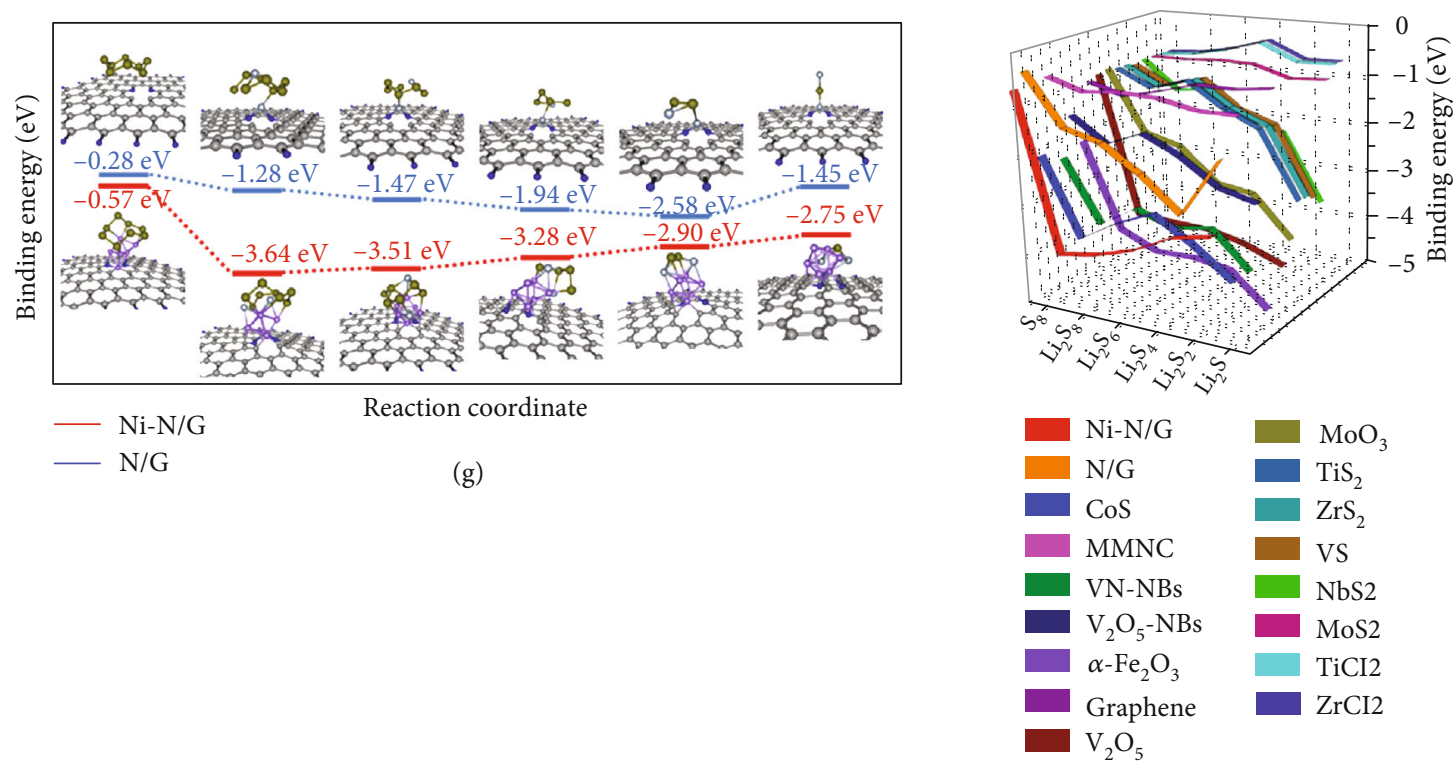

(h)

FIGURE 2: Structural characterizations and theoretical calculations. (a) Raman spectra and (b) $\mathrm{N}_{2}$ adsorption/desorption isotherms of Ni-N/G, N/G, Ni-N/C, and GNs. (c) Ni K-edge XANES spectra (inset, the enlarged spectra of Ni porphyrin and Ni-N/G) and (d) Ni $K$-edge $k^{3}$-weighted FT-EXAFS spectra of $\mathrm{Ni}$ foil, $\mathrm{NiO}$, and $\mathrm{Ni}$ porphyrin and Ni-N/G. Experimental testing and theoretical simulation of the polysulfide adsorption and conversion ability of Ni-N/G. (e) XPS S 2p spectra of $\mathrm{Li}_{2} \mathrm{~S}_{6}$ and $\mathrm{Li}_{2} \mathrm{~S}_{6} / \mathrm{Ni}-\mathrm{N} / \mathrm{G}$. (f) Structure of $\mathrm{Ni}_{6}-\mathrm{N} / \mathrm{C}$ used in first-principle calculations. (g) Binding geometric configurations and binding energies of sulfur species with the N/G and Ni-N/G. The high binding energies indicate the strong adsorption of Ni-N/G with sulfur species. (h) The binding energies between different lithium polysulfides and adsorbent materials, based on Ni-N/G compared with other currently reported sulfur host materials in the literature. Energy unit: electronvolts. Zero-point corrected. 
The valence states of isolated $\mathrm{C}, \mathrm{N}$, and $\mathrm{O}$ atoms were investigated by X-ray photoelectron spectroscopy (XPS). As indicated in the $\mathrm{C} 1 \mathrm{~s}$ and $\mathrm{N}$ 1s XPS spectra of Ni-N/G and N/G (Figures S13-S14), graphitic C dominates the $C$ 1s spectrum and nitrogen atoms doped into the graphene framework are present in the forms of pyridinic $(\sim 398.8 \mathrm{eV})$, pyrrolic $(\sim 400.2 \mathrm{eV})$, graphitic $(\sim 401.5 \mathrm{eV})$, and oxidized $(\sim 403.3 \mathrm{eV}) \mathrm{N}$ species [11]. As shown in the $\mathrm{N}$ 1s XPS spectra and element content of $\mathrm{Ni}-\mathrm{N} / \mathrm{C}$ and GNs (Figures S15-S16 and Tables S3-S4), when $\mathrm{N}_{2}$ was the only nitrogen source, pyrrolic $\mathrm{N}$ and graphitic $\mathrm{N}$ dominate in GNs; after the introduction of dimethylimidazole, pyridinic nitrogen becomes the main nitrogen form in Ni-N/C. Thus, it can be drawn that pyridinic nitrogen was mainly derived from the preserved $\mathrm{Ni}-\mathrm{N}$ structure in carbonizing $\mathrm{Ni}$-doped ZIFs, while the pyrrolic nitrogen and graphitic nitrogen were mainly introduced by $\mathrm{N}_{2}$. Furthermore, Ni-N/G possesses a high content of graphitic carbon and graphitic nitrogen, introducing extra electrons into the delocalized system, which can significantly improve the conductivity [23].

To further investigate the chemical state and local coordination structure of $\mathrm{Ni}$ atoms in $\mathrm{Ni}-\mathrm{N} / \mathrm{G}, \mathrm{X}$-ray absorption near-edge structure (XANES) and extended X-ray fine structure (EXAFS) spectroscope measurements were employed (Figures 2(c) and 2(d) and Figure S17). The results for Ni$\mathrm{N} / \mathrm{G}$ are shown along with those for the reference sample $\mathrm{Ni}$ foil, $\mathrm{NiO}$, and $\mathrm{Ni}$ porphyrin (Figure 2(c)). The XANES profile of Ni-N/G shows a significant difference from those of the reference samples. The preedge peak at $8338 \mathrm{eV}$ in the XANES is a fingerprint featuring the $\mathrm{Ni}-\mathrm{N}_{4}$ square planar $\mathrm{D}_{4 \mathrm{~h}}$ symmetry in the reference $\mathrm{Ni}$ porphyrin (Figure 2(c), inset). But the corresponding preedge peak in $\mathrm{Ni}-\mathrm{N} / \mathrm{G}$ is rather weak due to the serious distortion of the $\mathrm{Ni}-\mathrm{N}_{4}$ planar structure or replacement of integrant $\mathrm{N}$ atoms [24]. The $K$-edge WL intensities of $\mathrm{Ni}-\mathrm{N} / \mathrm{G}$ are between those of the reference samples $\mathrm{Ni}$ foil and $\mathrm{NiO}$, indicating that $\mathrm{Ni}$ atoms in Ni-N/G are positively charged.

The coordination environment of $\mathrm{Ni}$ atoms in $\mathrm{Ni}-\mathrm{N} / \mathrm{G}$ was further elucidated by Fourier transformations (FT) of $k^{3}$-weighted EXAFS (FT-EXAFS) (Figure 2(d)) [24, 25]. The oscillation of Ni-N/G is similar to that of bulk Ni, confirming that Ni clusters are in similar atomic local structure configuration of bulk Ni. But the amplitude of the Ni sample is expected to attenuate significantly with respect to the reference bulk sample, indicating the reduced size and decrease in the average coordination number [26]. Meanwhile, compared to the FTEXAFS of the reference Ni porphyrin, which shows a symmetric FT peak $\left(\mathrm{Ni}-\mathrm{N}_{4}\right)$, Ni-N/G has a well-separated FT peak featuring shorter and longer bond distances of $1.42 \AA$ and $2.08 \AA$, which correspond to $\mathrm{Ni}-\mathrm{N} / \mathrm{C}$ and $\mathrm{Ni}-\mathrm{Ni}$, respectively. With the EXAFS fitting process in $R$ and $k$ spaces, the coordination numbers of $\mathrm{Ni}-\mathrm{Ni}, \mathrm{Ni}-\mathrm{N}$, and $\mathrm{Ni}-\mathrm{C}$ in $\mathrm{Ni}-\mathrm{N} / \mathrm{G}$ are calculated to be $5.7( \pm 0.41), 0.33( \pm 0.05)$, and $0.54( \pm 0.05)$, respectively (Figure S17 and Table S5). Combining XAS analyses with the observation of TEM and HADDF-STEM, it is confirmed that $\mathrm{Ni}$ clusters are atomically embedded in the $\mathrm{N}$-doped 3D graphene framework and are coordinated by $\mathrm{N}$ atoms and $\mathrm{C}$ atoms to form $\mathrm{Ni}_{6}-\mathrm{N}-\mathrm{C}$ coordination centers.
2.2. Adsorption Experiments and Theoretical Calculations. To experimentally evaluate the adsorption ability of cell wall-like frameworks with LiPSs, a visualized adsorption test was conducted by adding Ni-N/G, N/G, Ni-N/C, and GNs into a solution of $0.005 \mathrm{M} \mathrm{Li}_{2} \mathrm{~S}_{6}$ in tetrahydrofuran (THF). And the $\mathrm{Li}_{2} \mathrm{~S}_{6} / \mathrm{THF}$ solution filled in a blank vial without any addition was regarded as a comparison. As shown in Figure S18, the Ni-N/G sample with $\mathrm{Ni}$ clusters has almost decoloured the LiPS solution after the mixture was settled down for $4 \mathrm{~h}$, which is much more obvious than other control samples. The interaction between $\mathrm{Ni}-\mathrm{N} / \mathrm{G}$ and $\mathrm{Li}_{2} \mathrm{~S}_{6}$ was investigated by X-ray photoelectron spectroscopy (XPS). The spectrum of $\mathrm{Li}_{2} \mathrm{~S}_{6}$ (Figure 2(e)) shows the $\mathrm{S} 2 \mathrm{p}_{3 / 2}$ at 161.9 and $163.3 \mathrm{eV}$, representing the terminal sulfur $\left(\mathrm{S}^{-1} \mathrm{~T}\right)$ and bridging sulfur $\left(S^{0} \mathrm{~B}\right)$, respectively [27]. The spectrum of $\mathrm{Li}_{2} \mathrm{~S}_{6}+\mathrm{Ni}-\mathrm{N} / \mathrm{G}$ exhibits two higher binding energy contributions at $162.2 \mathrm{eV}$ and $163.6 \mathrm{eV}$ (Figure 2(e)), representing a shift of $+0.3 \mathrm{eV}$ for both $\mathrm{S}^{-1} \mathrm{~T}$ and $\mathrm{S}^{0} \mathrm{~B}$, respectively. This can be explained by the fact that the polysulfide provides a large amount of electron density to the $\mathrm{Ni}$; thus, $\mathrm{S}$ has higher binding energy. Additionally, the significant enhancement of binding energy at $162.2 \mathrm{eV}$ is attributed to the interaction of elemental sulfur with Ni-N/G (forming Ni-S). These results provide strong evidence for the chemical bonding of the terminal and bridging sulfur between LiPSs and the Ni-N/G.

To understand the mechanism of superior reaction kinetics of charge/discharge of the S@Ni-N/G cathode, density functional theory (DFT) simulation was conducted, where the binding energies of different LiPSs on Ni-N/G were investigated with N/G used as a reference [28, 29]. As shown in Figure S19, two optimized models of $\mathrm{N}$ doped GNs with and without Ni clusters were considered in our simulation. Experimental results from XPS and XAS have shown that the Ni cluster is composed of six $\mathrm{Ni}$ atoms with the size of $\sim 0.1 \mathrm{~nm}$ and bonded to pyridinic $\mathrm{N}$ atoms and carbon atoms. The optimized structures of the intermediates trapped by Ni-N/G and N/G substrates are identified, respectively, as displayed in Figures 2(f) and $2(\mathrm{~g})$, and the binding energies between the Ni-N/G with $\mathrm{S}$ $(-0.57 \mathrm{eV}), \mathrm{Li}_{2} \mathrm{~S}_{8}(-3.64 \mathrm{eV}), \mathrm{Li}_{2} \mathrm{~S}_{6}(-3.51 \mathrm{eV}), \mathrm{Li}_{2} \mathrm{~S}_{4}(-3.28 \mathrm{eV})$, $\mathrm{Li}_{2} \mathrm{~S}_{2}(-2.90 \mathrm{eV})$, and $\mathrm{Li}_{2} \mathrm{~S}(-2.75 \mathrm{eV})$ species are calculated to be much higher than those of N/G (Table S6). These results suggest the strong interactions between the Ni-N/G composite and sulfur species, well consistent with the experimental adsorption.

During the discharging process, the binding energy of $\mathrm{Li}_{2} \mathrm{~S}_{8}-\mathrm{Ni}_{6}-\mathrm{N}-\mathrm{C}(-3.64 \mathrm{eV})$ is much more negative than that of $\mathrm{S}_{8}-\mathrm{Ni}_{6}-\mathrm{N}-\mathrm{C}(-0.57 \mathrm{eV})$, indicating that the spontaneous exothermic conversion reaction from $\mathrm{S}_{8}$ into $\mathrm{Li}_{2} \mathrm{~S}_{8}$ is kinetically fast [11]. In the subsequent steps to form $\mathrm{Li}_{2} \mathrm{~S}_{6}, \mathrm{Li}_{2} \mathrm{~S}_{4}$, $\mathrm{Li}_{2} \mathrm{~S}_{2}$, and $\mathrm{Li}_{2} \mathrm{~S}$, the binding energy of the reactants is always greater than that of the products, which helps kick off the products from the catalytic $\mathrm{Ni}_{6}$ sites and thus speed up the conversion of LiPSs, especially the immobilized $\mathrm{Li}_{2} \mathrm{~S}_{2} / \mathrm{Li}_{2} \mathrm{~S}$. In the charging process, the immobilized $S$ at the active site can also be easily replaced by polysulfides, due to the huge binding energy gap. The binding energies between different lithium polysulfides and substrates based on Ni-N/G are compared with those from other currently reported sulfur 
host materials (Figure 2(h) and Table S6) [13-17]. For the phase transition process (Equations (1) and (2)), it is clearly a process of entropy reduction. According to the Gibbs free energy (Equation (3)), only when $\Delta H \ll 0$ can the process happen spontaneously. Unfortunately, few sulfur host materials in the literature meet this requirement, whereas the binding energy of $\mathrm{Li}_{2} \mathrm{~S}_{8}$ on $\mathrm{Ni}-\mathrm{N} / \mathrm{G}$ is much stronger than that of $\mathrm{Li}_{2} \mathrm{~S}_{2} / \mathrm{Li}_{2} \mathrm{~S}$, reducing the energy barriers in liquid-solid phase transformations. Therefore, the integrated $\mathrm{Ni}_{6}-\mathrm{N}-\mathrm{C}$ configuration in the $\mathrm{Ni}-\mathrm{N} / \mathrm{G}$ composite has multifunctions: selectively adsorbing the soluble polysulfide, expediting the liquid-solid phase transformations, and accelerating the kinetics of polysulfide redox, demonstrating the application potential in enhancing the performance of Li-S batteries.

$$
\begin{aligned}
\mathrm{Li}_{2} \mathrm{~S}_{8(\mathrm{l})} & +\mathrm{Li}_{2} \mathrm{~S} @ \operatorname{Site}_{(\mathrm{s})} \longrightarrow \mathrm{Li}_{2} \mathrm{~S}_{8} @ \mathrm{Site}_{(\mathrm{s})}+\mathrm{Li}_{2} \mathrm{~S}_{(\mathrm{s})} \\
\Delta H & =E_{\mathrm{b}}\left(\mathrm{Li}_{2} \mathrm{~S}_{8} @ \operatorname{Site}_{(\mathrm{s})}\right)-E_{\mathrm{b}}\left(\mathrm{Li}_{2} \mathrm{~S} @ \operatorname{Site}_{(\mathrm{s})}\right), \\
\Delta G & =\Delta H-T \Delta S .
\end{aligned}
$$

2.3. Electrochemical Properties. To reveal the electrochemical conversion kinetics of LiPSs on Ni-N/G, N/G, Ni-N/C, and GN electrodes, cyclic voltammetry $(\mathrm{CV})$ of symmetric cells was conducted in $0.5 \mathrm{M}$ Li2S6 electrolyte, with a voltage window of -1.4 and $1.4 \mathrm{~V}$ and a scan rate of $10 \mathrm{mV} \mathrm{s}-1$, using identical working and counter electrodes [11]. As shown in Figure $3(\mathrm{a})$, the CV curve of the Ni-N/G electrode exhibits four distinct redox peaks, which can be assigned to the electrochemical reactions of LiPSs on the electrodes. The peaks in the negative scan can be assigned to the reduction of $\mathrm{S}$ to soluble $\mathrm{Li}_{2} \mathrm{~S}_{6} / \mathrm{Li}_{2} \mathrm{~S}_{4}$ (peak $\mathrm{A},-0.29 \mathrm{~V}$ ) and the further reduction into insoluble $\mathrm{Li}_{2} \mathrm{~S}_{2} / \mathrm{Li}_{2} \mathrm{~S}$ (peak $\mathrm{B},-0.75 \mathrm{~V}$ ) on the working electrode, whereas the peaks in the positive scan are accompanied by the decomposition of $\mathrm{Li}_{2} \mathrm{~S}_{2} / \mathrm{Li}_{2} \mathrm{~S}$, the reconstitution of $\mathrm{Li}_{2} \mathrm{~S}_{6} / \mathrm{Li}_{2} \mathrm{~S}_{4}$ (peak $\mathrm{C}, 0.29 \mathrm{~V}$ ), and further the oxidation to generate elemental $S$ (peak D, $0.82 \mathrm{~V}$ ) [11]. The CV curves of N/G, Ni-N/C, and GN electrodes also show four redox peaks, but the intensities are much lower, and the voltage differences between the cathodic and anodic peaks are higher than those of Ni-N/G. Thus, these CV curves conducted on symmetric cells demonstrate that the $\mathrm{Ni}$ hexatomic cluster plays a critical role in improving electrochemical kinetics of LiPS conversion.

The electrochemical properties of S@Ni-N/G and the control samples as sulfur cathodes were evaluated systematically through assembling Li-S coin cells. Figure 3(b) demonstrates the cyclic voltammetry $(\mathrm{CV})$ curves of S@Ni-N/G, S@N/G, S@Ni-N/C, and S@GN cathodes with the sulfur loading of $1.0 \mathrm{mg} \mathrm{cm}^{-2}$ at a scanning rate of $0.2 \mathrm{mV} \mathrm{s}^{-1}$ [30]. It can be identified that there are two cathodic peaks and one anodic peak in the CV curve of the S@Ni-N/G cell. The cathodic peak at $2.28 \mathrm{~V}$ is attributed to the formation of soluble polysulfides $\left(\mathrm{Li}_{2} \mathrm{~S}_{x}, 4<x \leq 8\right)$ from sulfur, and the peak at $2.02 \mathrm{~V}$ is ascribed to the formation of insoluble sulfides $\left(\mathrm{Li}_{2} \mathrm{~S}_{2}\right.$ and $\left.\mathrm{Li}_{2} \mathrm{~S}\right)$, respectively. The single anodic peak at $2.32 \mathrm{~V}$ is due to the one-step oxidation of $\mathrm{Li}_{2} \mathrm{~S}_{/} \mathrm{Li}_{2} \mathrm{~S}_{2}$ into $\mathrm{S}_{8}$
[14]. In comparison, the CV curves of the cells with the control samples exhibit an obvious negative shift for the two reduction peaks, a positive shift for the single oxidation peak, and lower current density. To further confirm the electrocatalytic effect of Ni-N/G on the electrochemical redox conversion of LiPSs, the onset potentials were taken at a current density of $10 \mu \mathrm{A} \mathrm{cm}^{-2}$ according to previous reports (Figure S20) [13, 15]. Compared to S@N/G, S@Ni-N/C, and S@GN control samples, the introduction of Ni clusters increases the onset potentials of cathodic peaks and decreases that of the anodic peak. Since the Ni-N/G and N/G cells have identical test conditions, their overpotential difference is mainly attributed to the existence of $\mathrm{Ni}_{6}$ catalytic sites. These results demonstrate that the Ni-N/G structure can significantly improve the utilization of sulfur species, accelerate electrocatalytic effect, and enhance LiPS redox kinetics. In addition, four $\mathrm{CV}$ curve cycles were performed to investigate the reversibility of the S@Ni-N/G cathode in Figure S21. Compared with the initial CV cycle, the following ones remain almost unchanged, implying the good cycling stability of the S@Ni-N/G cathode.

Figure 3(c) shows the galvanostatic charge/discharge profiles of the four electrodes with $\mathrm{S}$ mass loading of $1.0 \mathrm{mg} \mathrm{cm}^{-2}$. The S@Ni-N/G electrode possesses a considerably high initial discharge capacity of $1204 \mathrm{mAhg}^{-1}$ at $0.2 \mathrm{C}$. When the current rate increases to $0.5,1$, and $2 \mathrm{C}$, the discharge capacities of the S@Ni-N/G cathode achieve 967, 822, and $625 \mathrm{mAhg}^{-1}$, respectively (Figures 3(d) and Figure S22). Conversely, the discharge capacities of the control samples are seriously attenuated under the same condition, indicating the modified rate performance of S@Ni-N/G. Figure 3(e) displays the cycle performance of S@Ni-N/G, S@N/G, and S@GN cathodes with a charge/discharge capacity limited to $600 \mathrm{mAh} \mathrm{g}^{-1}$ at $430 \mathrm{~mA} \mathrm{~g}^{-1}$. It shows that the S@Ni-N/G anode with Ni clusters can hold the capacity of $600 \mathrm{mAhg}^{-1}$ for 400 cycles, whereas the S@N/G and S@GN cathodes perform 190 and 245 cycles with the capacity of $600 \mathrm{mAh} \mathrm{g}^{-1}$. The significantly longer cycle life of the S@Ni-N/G indicates that the integrated $\mathrm{Ni}_{6}-\mathrm{N}-\mathrm{C}$ configuration in the $\mathrm{Ni}-\mathrm{N} / \mathrm{G}$ composite provides stronger chemisorption of LiPSs, which ensures a great capability to restrict polysulfide dissolution and thus a superior cycling performance.

At a higher rate of $1.0 \mathrm{C}$, the $\mathrm{S} @ \mathrm{Ni}-\mathrm{N} / \mathrm{G}$ cathode still delivers the highest initial discharge capacity of $854.9 \mathrm{mAh} \mathrm{g}^{-1}$ and maintains at $537.5 \mathrm{mAh} \mathrm{g}^{-1}$ after 400 cycles (Figure S23). The resistance characteristics of these cathodes were investigated by electrochemical impedance spectroscopy (EIS) (Figure S24 and Tables S7-S8). Benefitting from the high content of graphitic carbon and graphitic nitrogen in the materials, these cathodes exhibit small charge transfer resistance. After 400 cycles, the diffusion resistance of the control sample is significantly enlarged or the display frequency regions become limited, indicating that the chemical system dynamics become sluggish [31]. The S@NiN/G cathode maintains very low charge transfer resistance, indicating that the $\mathrm{N}$ doping and the catalytic effect of $\mathrm{Ni}$ monoatoms can facilitate the electron transportation and accelerate the kinetics of polysulfide conversion [11]. In order 

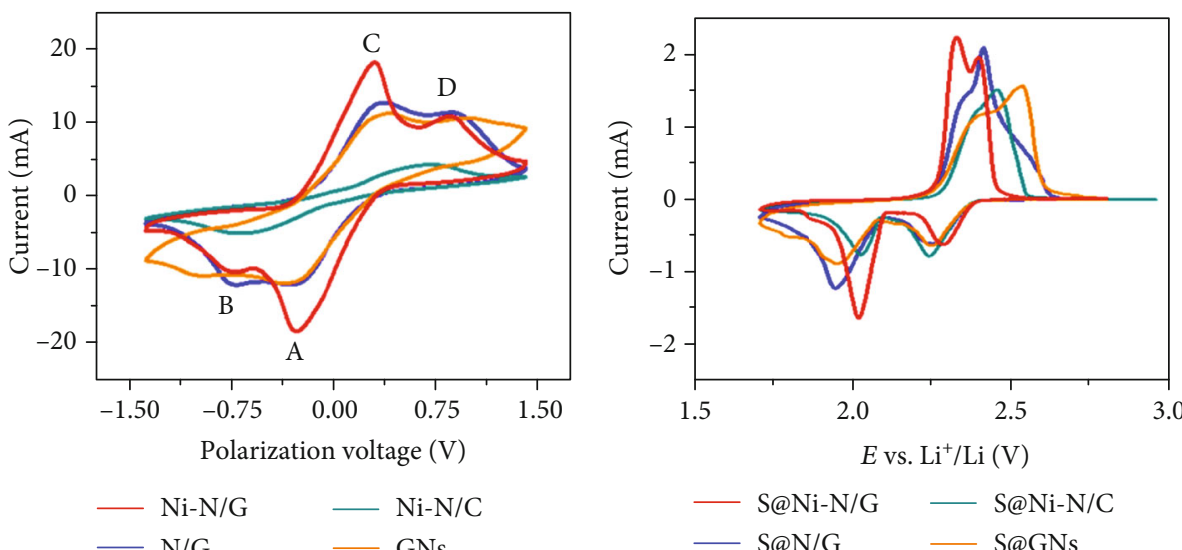

(a)

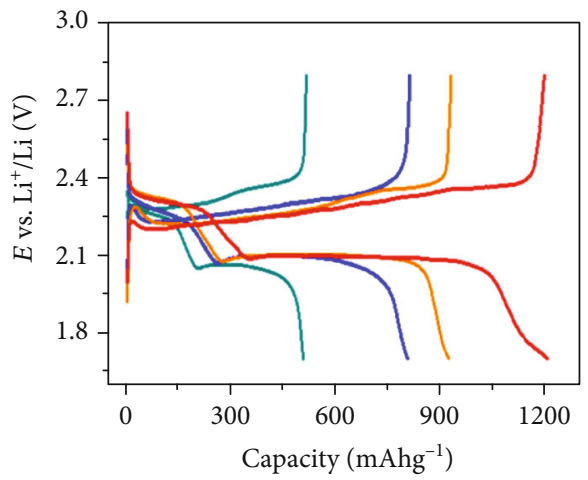

(b)

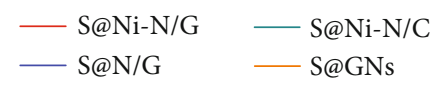

(c)
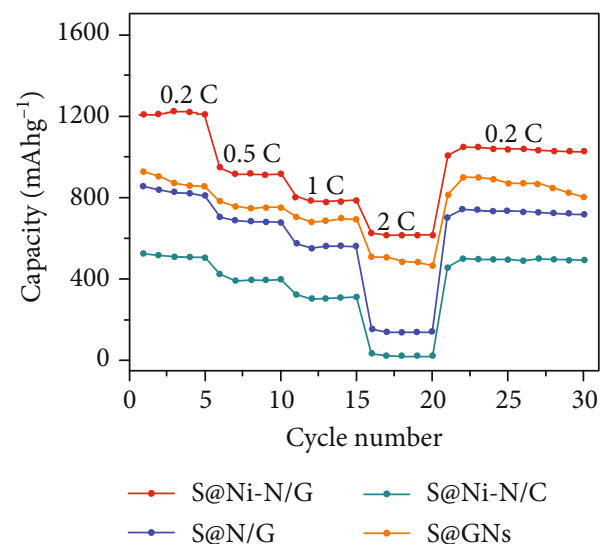

(d)

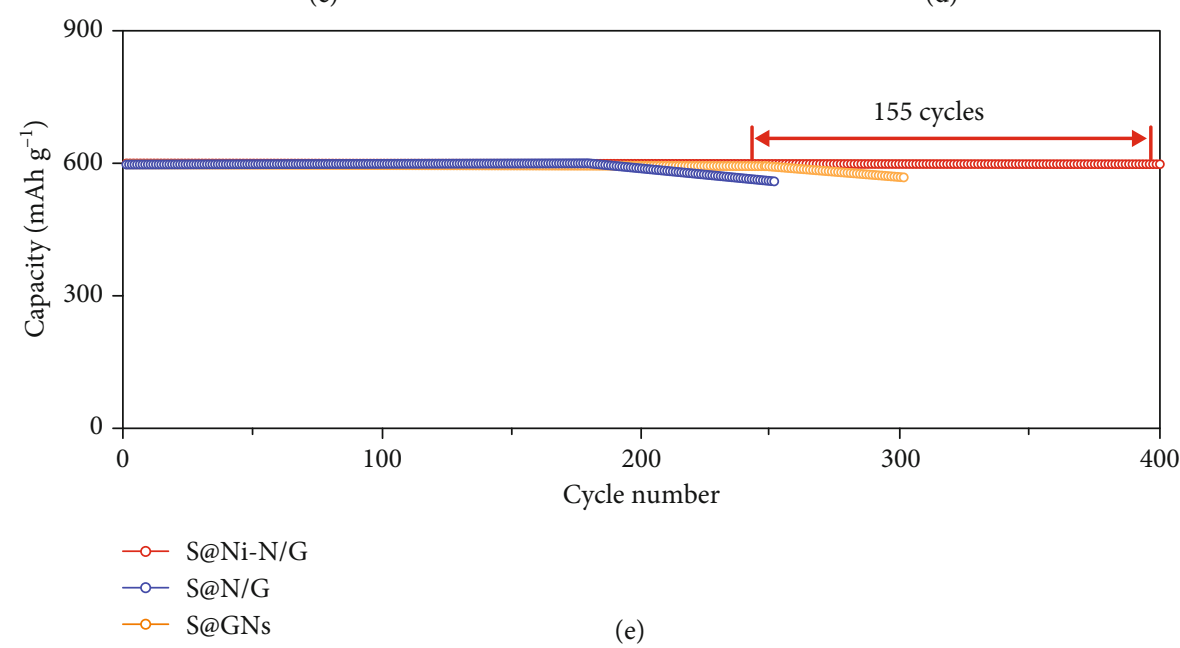

Figure 3: Electrochemical performances of S@Ni-N/G, S@N/G, S@Ni-N/C, and S@GN cathodes in Li-S batteries with the sulfur loading of $1.0 \mathrm{mg} \mathrm{cm}^{-2}$. (a) CV curves of symmetric cells over a voltage between -1.4 and $1.4 \mathrm{~V}$ with a sweep rate of $10 \mathrm{mV} \mathrm{s}^{-1}$. (b) $\mathrm{CV}$ curves over a voltage range of 1.7-2.8 $\mathrm{V}$ with a sweep rate of $0.2 \mathrm{mV} \mathrm{s}^{-1}$. (c) Discharge-charge profiles, (d) rate capabilities, and (e) cycle performance with limited discharge capacity of $600 \mathrm{mAh} \mathrm{g}^{-1}$ at $430 \mathrm{~mA} \mathrm{~g}^{-1}$.

to illustrate the contribution of Ni-N/G to the total discharge capacity of Li-S batteries, Ni-N/G (without the filling of sulfur) was tested as the cathode material for LIBs within a voltage window of $1.7-2.8 \mathrm{~V}$ vs. $\mathrm{Li} / \mathrm{Li}^{+}$(Figure S25). The mingy specific capacities indicate that the pristine $\mathrm{Ni}-\mathrm{N} / \mathrm{G}$ has almost no lithium storage capacity.
According to the U.S. Department of Energy (DOE), lithium-ion batteries must meet the following requirements for large-scale EES: shorter discharge times (from seconds to 6 hours), high energy densities, high efficiency (60-95\%), and low self-discharge compared to other storage technology types [32-34]. In consideration of these factors, cathodes 


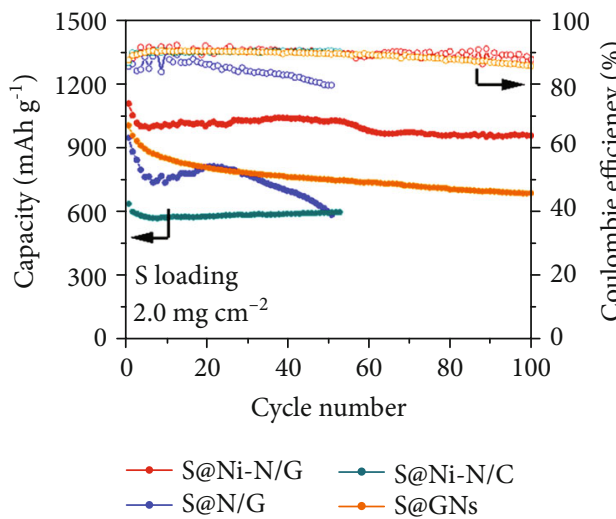

(a)

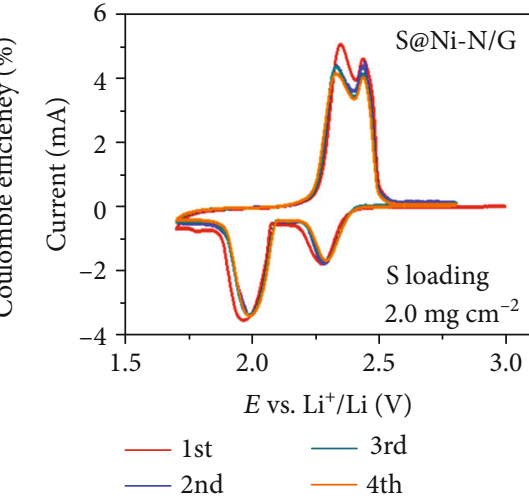

(b)

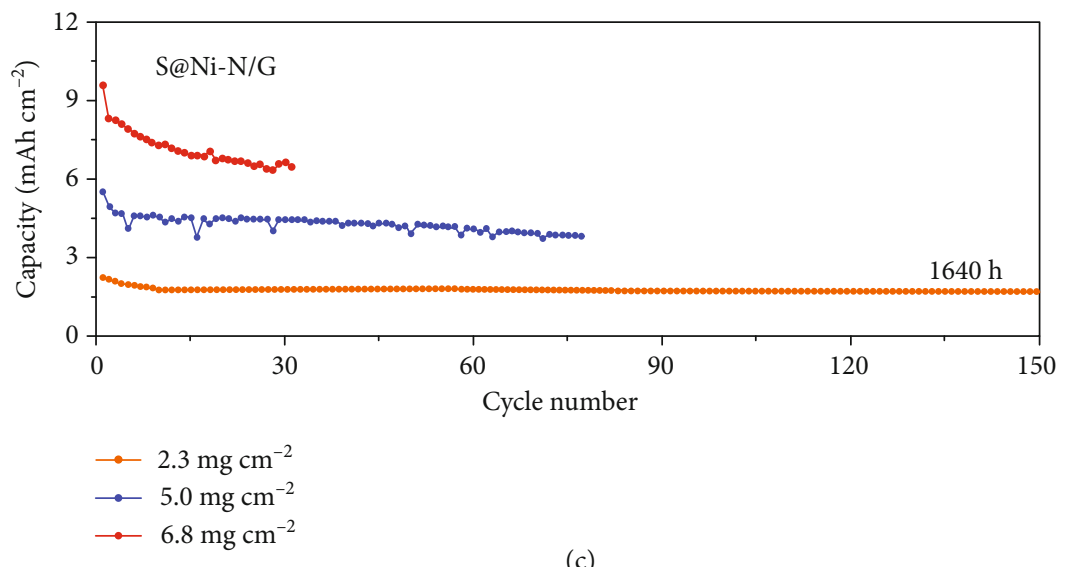

(c)

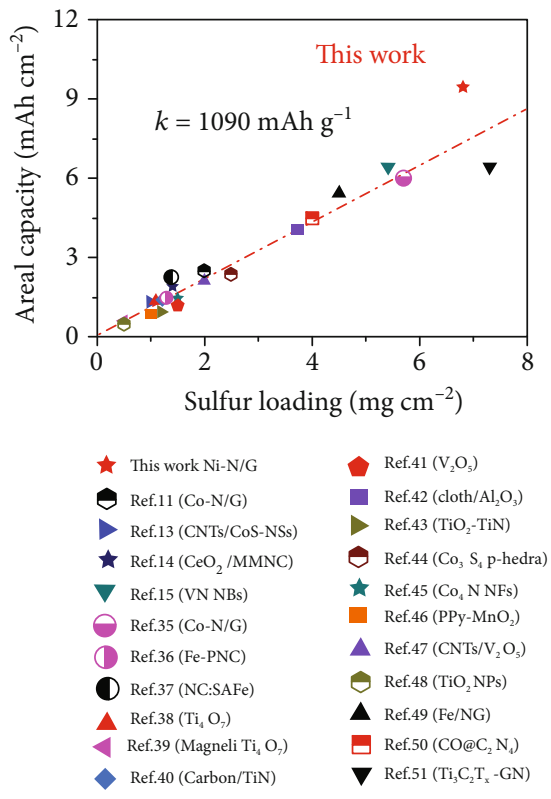

(d)

Figure 4: Electrochemical performances with high areal loading of sulfur. (a) Cycling performances and Coulombic efficiencies of S@Ni-N/G and control cathodes under $0.2 \mathrm{C}$. (b) $\mathrm{CV}$ curves over a voltage range of $1.7-2.8 \mathrm{~V}$ with sweep rate of $0.2 \mathrm{mV} \mathrm{s}^{-1}$. (c) Cycling performance of S@Ni-N/G with different areal loading of sulfur at 0.1 C. (d) Areal capacity of the S@Ni-N/G cathode with sulfur loading of 6.8 mg $\mathrm{cm}^{-2}$ at $0.1 \mathrm{C}$ compared with that of other currently reported sulfur host materials with catalytic properties in the literature.

with higher areal sulfur loading weights are called for. Figure 4(a) presents the cycling performances of S@Ni-N/G and control samples with the sulfur loading of $2.0 \mathrm{mg} \mathrm{cm}^{-2}$ under 0.2 C. The S@Ni-N/G cathode delivers an initial discharge capacity of $1103.6 \mathrm{mAh} \mathrm{g}^{-1}$, and it maintains a stable cycling performance $\left(953.5 \mathrm{mAh}^{-1}\right)$ and high Coulombic 
efficiency of $97 \%$ after 100 cycles. In contrast, the discharge capacities and Coulombic efficiency of the other three control cathodes decrease significantly during the cycles. The CV curves of the S@Ni-N/G cathode exhibit high peak current intensity $(\sim 3.4 \mathrm{~mA})$ and small voltage hysteresis between redox peaks (Figure 4(b)). Moreover, the excellent reversibility of $\mathrm{CV}$ curves indicates the good cycling stability of the S@Ni-N/G thick cathode.

To explore the practical application of S@Ni-N/G, the $S$ mass loading was further increased to 2.3, 5.0, and $6.8 \mathrm{mg} \mathrm{cm}^{-2}$ in cathodes at $0.1 \mathrm{C}$, corresponding to $0.39,0.84$, and $1.14 \mathrm{~mA} \mathrm{~cm}^{-2}$, respectively (Figures 4(c) and Figure S26). The composites delivered initial areal specific capacities of 2.22, 5.52, and $9.43 \mathrm{mAh} \mathrm{cm}^{-2}$. Most interestingly, it is found statistically that the positions of the reported sulfur cathode materials are distributed in a straight line with a slope of $1090 \mathrm{mAh} \mathrm{g}^{-1}$, and the Ni-N/G composite is located above the straightness, indicating its superior performance (Figure 4(d) and Table S9) [11, 13-15, 35-51]. Moreover, the S@Ni-N/G cathode with high sulfur loading of $2.3 \mathrm{mg} \mathrm{cm}^{-2}$ under $0.1 \mathrm{C}$ shows good cycling performances and deliver the discharge capacities of $734 \mathrm{mAh} \mathrm{g}^{-1}$ after cycling for 150 cycles, namely, $1460 \mathrm{~h}$, and the corresponding capacity retentions are $76.1 \%$ compared to the initial cycle. The outstanding performances of S@Ni-N/G cathodes with high sulfur loading are ascribed to the strong polysulfide adsorption/confinement, high specific surface, and high conductivity provided by codoped $\mathrm{Ni}-\mathrm{N}$ atoms and the $3 \mathrm{D}$ graphene framework, which facilitate the electron/ion transport and ensure the efficient sulfur utilization in the thick electrodes.

On the basis of the excellent charge/discharge performance of Ni-N/G composite at $0.1 \mathrm{C}$, a soft-packed Li-S battery of the S@Ni-N/G cathode was assembled with a correspondingly shaped Celgard membrane and lithium foil as the separator and anode, respectively. The sandwich structure was sealed by $\mathrm{Al}$ plastic films straight after injecting electrolyte, with the total weight of $2.37 \mathrm{~g}$ (Figure S27). The cycling performance test of the S@Ni-N/G soft-packed battery was divided into two phases: first five cycles at $1.94 \mathrm{~mA}$ and then the following cycles at $6.45 \mathrm{~mA}$. The initial discharge capacity reached $51.4 \mathrm{mAh}\left(6.1 \mathrm{mAh} \mathrm{cm}^{-2}\right)$ and thereafter tended to be stable to $20.7 \mathrm{mAh}\left(2.5 \mathrm{mAh} \mathrm{cm}^{-2}\right)$. The corresponding average Coulombic efficiency was up to $96 \%$, suggesting the fine suppression of the polysulfide shuttle effect and the potential of the Ni-N/G composite in the practical application of EES.

\section{Conclusion}

In summary, $\mathrm{Ni}$ hexatomic clusters embedded in the $\mathrm{N}$ doped 3D graphene framework were prepared as both polysulfide adsorbents and electrocatalysts in rechargeable Li-S batteries. Ni-N/G displays significant selectivity differences in the adsorption of soluble and insoluble polysulfides. The selective adsorption and catalytic properties were proven by experimental measurements and density functional theory (DFT) calculations. When deployed in the sulfur cathode, the S@Ni-N/G cathode possesses the following merits: (i) atomically dispersed $\mathrm{Ni}$ derived from metal doped ZIF-8 effectively acts as an anchoring conversion center of LiPSs, (ii) the crisscrossed 3D hierarchically graphene framework and nitrogen doping ensure good stability and small charge transfer resistance, and (iii) the porous nanostructure enables high sulfur loading and accommodates the volume change of sulfur. This work figures out one approach to design an electrocatalyst to selectively adsorb and convert polysulfides for high performance of Li-S batteries.

\section{Materials and Methods}

4.1. Reagents. Anhydrous sodium carbonate $\left(\mathrm{Na}_{2} \mathrm{CO}_{3}\right)$, hydrochloric acid $(\mathrm{HCl})$, nickel nitrate hexahydrate $\left(\mathrm{Ni}\left(\mathrm{NO}_{3}\right)_{2} \cdot 6 \mathrm{H}_{2} \mathrm{O}\right)$, zinc nitrate hexahydrate $\left(\mathrm{Zn}\left(\mathrm{NO}_{3}\right)_{2} \cdot 6 \mathrm{H}_{2} \mathrm{O}\right)$, and absolute methanol $\left(\mathrm{CH}_{3} \mathrm{OH}\right)$ were obtained from Shanghai Chemical Reagents, China. Sublimed sulfur, N-methyl pyrrolidone (NMP), and 2-methylimidazol $\left(\mathrm{C}_{4} \mathrm{H}_{6} \mathrm{~N}_{2}, 98 \%\right)$ were purchased from Aladdin. Sodium gluconate was acquired from 3A Chemicals of Shanghai, China. Polyvinylidene fluoride (PVDF) and Super P Li were obtained from Taiyuan Yingze District Lizhiyuan Battery Sales Department. Lithium sulfur electrolyte (LS009) containing 1.0 M bis(trifluoromethane) sulfonamide lithium salt (LiTFSI) in a mixed solvent of dimethoxyethane and 1,3-dioxolane (DME/DOL, 1:1 volume ratio) with $2 \mathrm{wt} \%$ of lithium nitrate was purchased from the DoDoChem. The chemicals of this experiment were of analytical grade without further purification.

4.2. Synthesis of Ni-ZIF and ZIF. Ni-doped ZIF precursors were synthesized at $60^{\circ} \mathrm{C}$ in a methanol solution. $\mathrm{Ni}\left(\mathrm{NO}_{3}\right)_{2}$. $6 \mathrm{H}_{2} \mathrm{O}(72 \mathrm{mg})$ and $\mathrm{Zn}\left(\mathrm{NO}_{3}\right)_{2} \cdot 6 \mathrm{H}_{2} \mathrm{O}(3.39 \mathrm{~g})$ were dissolved in $600 \mathrm{~mL}$ methanol (marked A). 2-Methylimidazole (3.94 g) was dissolved in $600 \mathrm{~mL}$ methanol (marked B). Next, A was poured into $\mathrm{B}$ and sealed. The mixed solution was heated to $60^{\circ} \mathrm{C}$ and maintained for $24 \mathrm{~h}$. Then, centrifugation was performed to collect the precipitant with thorough ethanol washing, and the precipitant was dried at $60^{\circ} \mathrm{C}$ in a vacuum oven for $12 \mathrm{~h}$. The only difference between the synthesis of ZIF and $\mathrm{Ni}$ ZIF was that ZIF synthesis did not use $\mathrm{Ni}\left(\mathrm{NO}_{3}\right)_{2} \cdot \mathrm{H}_{2} \mathrm{O}$.

4.3. Synthesis of $N i-N / G, N / G, N i-N / C$, and GNs. Ni-N/G was synthesized by a molten salt method. Ni-doped ZIF (1 g), $\mathrm{Na}_{2} \mathrm{CO}_{3}$ (10g), and sodium gluconate $(5 \mathrm{~g})$ were mixed together and ground in uniformity. Subsequently, the mixed precipitant was heated in a tube furnace under $\mathrm{N}_{2}$ flow from room temperature to $950^{\circ} \mathrm{C}$ with $3^{\circ} \mathrm{C} \mathrm{min}^{-1}$ and kept at $950^{\circ} \mathrm{C}$ for $10 \mathrm{~min}$. The acquired black mixture needed to react with $3 \mathrm{~mol} \mathrm{~L}^{-1} \mathrm{HCl}$ solution until no bubbles appeared, and then, using DI water, the Ni-N/G was washed adequately to neutral. Finally, the precipitant was dried at $60^{\circ} \mathrm{C}$ for $12 \mathrm{~h}$. The synthesis method of N/G was the same as Ni-N/G synthesis. The only difference was the replacement of Ni-doped ZIF $(1 \mathrm{~g})$ with ZIF $(1 \mathrm{~g})$. The synthesis method of Ni-N/C was the same as Ni-N/G synthesis. The only difference was that $\mathrm{Ni}-\mathrm{N} / \mathrm{C}$ synthesis did not use $\mathrm{Na}_{2} \mathrm{CO}_{3}(10 \mathrm{~g})$ and sodium gluconate $(5 \mathrm{~g})$. The synthesis method of GNs was the same as Ni-N/G synthesis. The only difference was that the pristine 
ZIF-8 (1 g) precursor was mixed with $\mathrm{Na}_{2} \mathrm{CO}_{3}(10 \mathrm{~g})$ and sodium gluconate $(5 \mathrm{~g})$.

\subsection{Polysulfide Static Adsorption Test and XPS Sample} Preparation. $\mathrm{Li}_{2} \mathrm{~S}_{6}$ was prepared by dissolving sublimed sulfur and lithium sulfide in tetrahydrofuran (THF) at a molar ratio of $5: 1$ under stirring. Then, the $\mathrm{Li}_{2} \mathrm{~S}_{6} / \mathrm{THF}$ solution was dried at $35^{\circ} \mathrm{C}$ to acquire yellow powder $\mathrm{Li}_{2} \mathrm{~S}_{6}$. All procedures were performed in an Ar-filled glovebox. The static adsorption test was performed by adding Ni-N/G, $\mathrm{N} / \mathrm{G}, \mathrm{Ni}-\mathrm{N} / \mathrm{C}$, and GNs with the same weight of $10 \mathrm{mg}$ into the sealed vials containing $\mathrm{Li}_{2} \mathrm{~S}_{6}(0.005 \mathrm{M})$ in $10 \mathrm{~mL}$ tetrahydrofuran (THF), respectively. Then, the mixtures were settled down for $4 \mathrm{~h}$ after shaking to observe the colour variation. The $\mathrm{Li}_{2} \mathrm{~S}_{6} / \mathrm{THF}$ solution, as a comparison, was filled in a blank vial without any addition. The XPS samples of Ni-N/G were acquired by heating the $\mathrm{Li}_{2} \mathrm{~S}_{6} / \mathrm{THF}$ solution containing Ni-N/G at $35^{\circ} \mathrm{C}$. All procedures were performed in an Ar-filled glovebox.

4.5. Material Characterization. X-ray diffractions (XRD) were recorded through an X'Pert PRO (PANalytical, Netherlands) instrument with $\mathrm{Cu} \mathrm{K}$ radiation over the $2 q$ range from $10^{\circ}$ to $80^{\circ}$. Raman spectroscopy was performed using a Laser Confocal Raman Microspectroscopy (LabRAM HR Evolution, HORIBA Jobin Yvon). X-ray photoelectron spectroscopy (XPS) analyses were conducted with an Escalab 250Xi XPS system with an $\mathrm{Al} \mathrm{K} \alpha(1486.6 \mathrm{eV})$ source. Scanning electron microscopy (SEM) was performed on a Hitachi S-4800 field emission scanning electron microscope (FE-SEM) $(5 \mathrm{kV})$. Transmission electron microscopy (TEM) and high-resolution transmission electron microscopy (HRTEM) were conducted with a JEM-2100F field emission TEM. Energy-dispersive X-ray (EDX) was obtained using JEOL-2200FS and double Cs-corrected STEM at the acceleration voltage of $200 \mathrm{kV}$. HAADF-STEM images were acquired on a FEI TITAN Chemi STEM equipped with a CEOS (Heidelberg, Germany) probe corrector, operating at $200 \mathrm{kV}$. The specific surface area and pore size distribution were measured by using nitrogen adsorption/desorption isotherms through the Brunauer-Emmett-Teller (BET, AUTOSORBIQ2-MP) method at $77 \mathrm{~K}$. The BJH method is selected to calculate the pore size distribution. Thermogravimetric analysis (TGA) was performed on a thermal analyzer (Pyris 1 TGA) in the temperature range from $50^{\circ} \mathrm{C}$ to $600^{\circ} \mathrm{C}$ under nitrogen flow. The X-ray absorption fine structure (XAFS) at the Ni K $\left(E_{0}=8333.0 \mathrm{eV}\right)$ edge was performed at the BL14W1 beamline of Shanghai Synchrotron Radiation Facility (SSRF) operated at $3.5 \mathrm{GeV}$ under the "top-up" mode with a constant current of $260 \mathrm{~mA}$. The XAFS data were recorded under a transmission mode with ion chambers. The energy was calibrated accordingly to the absorption edge of pure $\mathrm{Ni}$ foil. Athena and Artemis codes were used to extract the data and fit the profiles. For the X-ray absorption near-edge structure (XANES) part, the experimental absorption coefficients as function of energies $\mu(E)$ were processed by background subtraction and normalization procedures and reported as "normalized absorption" with $E_{0}=8333.0 \mathrm{eV}$ for the Ni-N/G sample, $\mathrm{Ni}$ foil, $\mathrm{NiO}$, and $\mathrm{Ni}$ porphyrin standard. For the extended X-ray absorption fine structure (EXAFS) part, the Fourier transformed (FT) data in the $R$ space were analyzed for Ni-Ni, Ni-N, and Ni-C contributions. The passive electron factors, $\mathrm{S}_{0}{ }^{2}$, were determined by fitting the experimental data on $\mathrm{Ni}$ foils and fixing the coordination number $(\mathrm{CN})$ of $\mathrm{Ni}$ $\mathrm{Ni}$ to be 12 and then fixed for further analysis of the measured samples. The parameters describing the electronic properties (e.g., correction to the photoelectron energy origin, $E_{0}$ ) and local structure environment including $\mathrm{CN}$, bond distance $(R)$, and Debye-Waller factor around the absorbing atoms were allowed to vary during the fitting process. The fitted ranges for $k$ and $R$ spaces were selected to be $k=2-9 \AA^{-1}$ with $R=1-3 \AA$ ( $k^{3}$ weighted). We set the initial amplitude attenuation factor $\mathrm{S}_{0}{ }^{2}$ to be 0.85 and the Debye-Waller factor $\sigma^{2}$ to be $0.003 \AA^{2}$ for all the analyzed $\mathrm{Ni}-\mathrm{Ni}, \mathrm{Ni}-\mathrm{N}$, and $\mathrm{Ni}-\mathrm{C}$ shells [25].

4.6. Electrochemical Tests. The sulfur was mixed with Ni-N/G and ground in uniformity. Then, the sulfur containing the $\mathrm{Ni}-\mathrm{N} / \mathrm{G}$ substrate was heated at $155^{\circ} \mathrm{C}$ for $4 \mathrm{~h}$ under an argon atmosphere. Other samples underwent the same procedure as Ni-N/G. Symmetric cells were assembled with two electrodes that consisted of a mixture of $80 \mathrm{wt} \%$ of the active material (Ni-N/G, N/G, Ni-N/C, or GNs) and $20 \mathrm{wt} \%$ of polyvinylidene fluoride (PVDF). The active material mass loading was $0.8-1.0 \mathrm{mg} \mathrm{cm}^{-2}$. The electrolyte was a dioxolane (DOL)/dimethoxyethane (DME) (volume ratio $1: 1$ ) mixture containing $1 \mathrm{M}$ LiTFSI, $0.5 \mathrm{M} \mathrm{Li}_{2} \mathrm{~S}_{6}$, and $2.0 \mathrm{wt} \% \mathrm{LiNO}_{3}$. Cyclic voltammetry $(\mathrm{CV})$ was performed between -1.4 and $1.4 \mathrm{~V}$ at the scan rate of $10 \mathrm{mV} \mathrm{s}^{-1}$. The Li-S batteries were assembled with both CR2025-type coin cells and softpackage batteries in an Ar-filled glovebox. To fabricate the working electrodes of Li-S batteries, a slurry was made by mixing the composite of S-loading Ni-N/G, conductive carbon additive (Super P), and a polymeric binder (PVDF) in a weight ratio of $7: 2: 1$ using NMP as the solvent. The prepared slurry was coated on the $\mathrm{Al}$ foil and dried at $60^{\circ} \mathrm{C}$ in the vacuum oven for $8 \mathrm{~h}$. Next, the electrode was cut into the shape of a coin by a punching machine. The average mass loading of the active materials on a pole piece was controlled in the range of $1.0 \mathrm{mg} \mathrm{cm}^{-2}$ to $6.8 \mathrm{mg} \mathrm{cm}$. When the mass loading of the active materials is greater than $3 \mathrm{mg} \mathrm{cm}^{-2}$, the prepared slurry is coated with nickel foam. Both reference and counter electrodes used lithium metal. And the polymeric porous membrane (polypropylene) was used as the separator. The electrolyte is critical to the performance of Li-S batteries. When the electrolyte is insufficient, the electrode and separator are not fully wetted, the active material utilization rate is low, and the ion conductivity is poor. However, the excessive electrolyte reduces the mass energy density of the battery. Moreover, the electrolyte and sulfur react to form soluble LiPS, which reduces the battery performance. Therefore, to maximize energy density, the amount of electrolyte used must be considered based on the sulfur content. Taking the above issues into consideration, this work chooses different amounts of LS009 electrolyte (20 and $10 \mu \mathrm{L} \mathrm{mg}^{-1}$ ) for low- and high-sulfur content. The galvanostatic chargedischarge measurements were performed in the LAND battery cycle test system with the potential range of 1.7 to $2.8 \mathrm{~V}$ (vs. 
$\left.\mathrm{Li} / \mathrm{Li}^{+}\right)$at different current densities in the range of 0.1 to $2 \mathrm{C}$ rate $\left(1 \mathrm{C}\right.$ rate $1675 \mathrm{~mA} \mathrm{~g}^{-1}$ ). The current density and capacity of the electrode were calculated based on the weight of sulfur in the electrode. Cyclic voltammetry (CV) analysis was performed at a scan rate of $0.1 \mathrm{mV} \mathrm{s}^{-1}$ from 1.7 to $2.8 \mathrm{~V}$ (vs. $\left.\mathrm{Li} / \mathrm{Li}^{+}\right)$on a $\mathrm{CHI} 660 \mathrm{E}$ electrochemical workstation $(\mathrm{CH}$ Instruments, China). Electrochemical impedance spectroscopy (EIS) was conducted in the frequency range from $0.01 \mathrm{~Hz}$ to $1000 \mathrm{kHz}$ with an amplitude of $5 \mathrm{mV}$.

4.7. Theory Calculation. In this work, the geometry optimization and frequency analysis were performed using the extended tight-binding semiempirical program package (xTB) $[28,29]$. The geometries were obtained with GFN0xTB, while the energies were given by GFN2-xTB. All stationary points were optimized without symmetry constraint, and their nature was confirmed by vibrational frequency analysis. The adsorption energy was defined as $E_{(\mathrm{ad})}=$ $E_{(\text {ad/surf })}-E_{(\text {surf })}-E_{(\text {ad) }}$, where $E_{(\text {ad/surf })}, E_{(\text {surf })}$, and $E_{(\text {ad })}$ are the total energies of the adsorbates binding to the surface, clean surface, and free adsorbate in the gas phase, respectively.

\section{Conflicts of Interest}

The authors declare that there is no conflict of interest regarding the publication of this article.

\section{Authors' Contributions}

J. Ji, X. Gao, and M. Ling conceived the idea. J. Ji and M. Ling designed the experiments. J. Ji and Y. Sha conducted the synthesis experiments and electrocatalytic tests. Z. Li helped to conduct the soft-package battery testing. T. Zhang, S. Zhou, and T. Qiu helped with characterization analysis. Shaodong Zhou conducted the theoretical calculation. L. Zhang helped with synchrotron radiation testing. J. Ji, M. Ling, Y. Hou, and C. Liang were involved in the discussion of all results and wrote the manuscript.

\section{Acknowledgments}

The authors would like to thank TPS (beamline 44A1) for the allocation of synchrotron beam time. This work was supported by the National Key R\&D Program of China (2018YFB0104300, 2016YFA0200102), National Natural Science Foundation of China $(51874104,51631001)$ and Key Technology and Supporting Platform of Genetic Engineering of Materials under State's Key Project of Research and Development Plan (2016YFB0700600).

\section{Supplementary Materials}

Figure S1: SEM images of (a) N/G, (b) Ni-N/C, and (c) GNs. Figure S2: (a) TEM and (b) high-resolution TEM (HRTEM) of the Ni-N/G composite. Figure S3: representative electron microscopy images. (a) TEM (inset, corresponding SAEDP) and (b) HRTEM images of the N/G sample. Figure S4: representative electron microscopy images. (a-b) TEM (inset (a), corresponding SAEDP) and (c) HRTEM images of the GN sample. Figure S5: representative electron microscopy images. (a) TEM (inset, corresponding SAEDP) and (b) HRTEM images of the Ni-N/C sample. Figure S6: (a) HAADF-STEM image of the Ni-N/G sample and (b) corresponding EDX maps (colours) of an individual element. Figure S7: (a) STEM image of the $N / G$ sample and (b-d) corresponding EDX maps (colours) of an individual element. Figure S8: (a) STEM image of the Ni-N/C sample and (b) corresponding EDX maps (colours) of an individual element. Figure S9: (a) STEM image of the GN sample and (b-d) corresponding EDX maps (colours) of an individual element. Figure S10: XRD patterns of Ni-N/G, N/G, Ni-N/C, and GNs. Figure S11: pore size distribution curves of Ni-N/G, N/G, Ni-N/C, and GNs. Figure S12: TGA curve of S@NiN/G, S@N/G, S@Ni-N/C, and S@GNs in an $\mathrm{N}_{2}$ atmosphere heated from room temperature to $600^{\circ} \mathrm{C}$ with the ramping rate of $10^{\circ} \mathrm{C} \mathrm{m^{-1 }}$. Figure S13: XPS high-resolution spectra of (a) C 1s, (b) N 1s, and (c) O 1s in Ni-N/G. Figure S14: XPS high-resolution spectra of (a) $\mathrm{C} 1 \mathrm{~s}$, (b) $\mathrm{N} 1 \mathrm{~s}$, and (c) $\mathrm{O}$ 1s in N/G. Figure S15: XPS high-resolution spectra of (a) C 1s, (b) N 1s, and (c) O 1s in Ni-N/C. Figure S16: XPS highresolution spectra of (a) C 1s, (b) $\mathrm{N} 1 \mathrm{~s}$, and (c) $\mathrm{O} 1 \mathrm{~s}$ in GNs. Figure S17: the EXAFS fitting in the $k$ space (a) and $R$ space (b) about the measured (green line) and fitting curves (red line) for Ni-N/G. Figure S18: experimental testing of the polysulfide adsorption of Ni-N/G, N/G, Ni-N/C, and GNs with Li2S6 as a representative lithium polysulfide. Figure S19: structure of N/G (a) and Ni-N/G (b) used in firstprinciple calculations. Figure S20: differential CV curves (ad) of S@Ni-N/G, S@N/G, S@Ni-N/C, and S@GN cathodes verified from the CV profiles in Figure 3(b). The corresponding onset potentials of re5dox peaks are attained at the current density of $10 \mu \mathrm{A} \mathrm{cm}{ }^{-2}$. The baseline potentials and baseline current densities are defined as the values before the redox peaks, where the variation on current density is the smallest, namely, $\mathrm{dI} / \mathrm{dV}=0$. Figure $\mathrm{S} 21$ : electrochemical performances (a-d) of S@Ni-N/G, S@N/G, S@Ni-N/C, and S@GN cathodes in Li-S batteries with the sulfur loading of $1.0 \mathrm{mg} \mathrm{cm}^{-2}$. CV curves over a voltage range of 1.7-2.8 $\mathrm{V}$ with a sweep rate of $0.2 \mathrm{mV} \mathrm{s}^{-1}$. Figure S22: typical dischargecharge profiles of the S@Ni-N/G composite at different current densities. Figure S23: electrochemical performances of S@Ni-N/G, S@N/G, S@Ni-N/C, and S@GN cathodes in Li$\mathrm{S}$ batteries with the sulfur loading of $1.0 \mathrm{mg} \mathrm{cm}^{-2}$. Longterm cycling performances and corresponding Coulombic efficiencies under 1.0 C. Figure S24: EIS spectra of S@NiN/G, S@N/G, S@Ni-N/C, and S@GN cathodes (a) before and (b) after long-term cycling, revealing the much smaller charge transfer resistance of the S@Ni-N/G cathode. Figure S25: cycling performance of Ni-N/G as the cathode material for LIBs within a voltage window of $1.7-2.8 \mathrm{~V}$ vs. $\mathrm{Li} / \mathrm{Li}+$. The ultralow specific capacities indicate that the lithium storage capacity of pristine Ni-N/G has no contribution to the total discharge capacity of Li-S batteries. Figure S26: cycling performance and Coulombic efficiencies of S@Ni-N/G with different areal loading of sulfur at 0.1 C. Figure S27: cycling performance and Coulombic efficiencies of the S@Ni-N/Gbased soft-packed Li-S battery at $0.1 \mathrm{C}$. Inset: the photograph of the soft-packed Li-S battery assembled with the S@Ni-N/G 
cathode and lithium foil anode. Table S1: atomic percentage ratios of different elements in Ni-N/G according to the EDX results of HADDF-STEM. Table S2: BET surface area, pore volume, and pore diameter of $\mathrm{Ni}-\mathrm{N} / \mathrm{G}, \mathrm{N} / \mathrm{G}$, $\mathrm{Ni}-\mathrm{N} / \mathrm{C}$, and GNs. Table S3: atomic percentage ratios of different elements in Ni-N/G and control samples according to the results of XPS. Table S4: atomic percentage ratios of different $\mathrm{N}$ types in $\mathrm{Ni}-\mathrm{N} / \mathrm{G}$ and control samples according to the results of XPS. Table S5: EXAFS parameters for $\mathrm{Ni}-\mathrm{N} / \mathrm{G}, \mathrm{Ni}$ foil, $\mathrm{NiO}$, and $\mathrm{Ni}$ porphyrin. Table S6: the binding energies between different lithium polysulfides and substrates, based on Ni-N/G compared with other currently reported sulfur host materials in the literature. Energy unit: electronvolts. Zero-point corrected. Table S7: summary of electrochemical impedance spectroscopy of the initial $\mathrm{Ni}-\mathrm{N} / \mathrm{G}, \mathrm{N} / \mathrm{G}, \mathrm{Ni}-\mathrm{N} / \mathrm{C}$, and $\mathrm{GN}$ samples at open-circuit voltage. Table S8: summary of electrochemical impedance spectroscopy of the Ni-N/G, $\mathrm{N} / \mathrm{G}, \mathrm{Ni}-\mathrm{N} / \mathrm{C}$, and $\mathrm{GN}$ samples at open-circuit voltage after 400 cycles at $1 \mathrm{C}$. Table S9: electrochemical performances of sulfur cathodes based on Ni-N/G compared with other currently reported sulfur host materials in the literature. (Supplementary Materials)

\section{References}

[1] S. Bai, X. Liu, K. Zhu, S. Wu, and H. Zhou, "Metal-organic framework-based separator for lithium-sulfur batteries," Nature Energy, vol. 1, no. 7, pp. 1-6, 2016.

[2] J. Zhou, R. Li, X. Fan et al., "Rational design of a metal-organic framework host for sulfur storage in fast, long-cycle Li-S batteries," Energy \& Environmental Science, vol. 7, no. 8, pp. 27152724, 2014.

[3] Z. Lin, T. Liu, X. Ai, and C. Liang, "Aligning academia and industry for unified battery performance metrics," Nature Communications, vol. 9, no. 1, p. 5262, 2018.

[4] T. Liu, Y. Zhang, Z. Jiang et al., "Exploring competitive features of stationary sodium ion batteries for electrochemical energy storage," Energy \& Environmental Science, vol. 12, no. 5, pp. 1512-1533, 2019.

[5] Z. Li, Y. Zhang, T. Liu et al., "Silicon anode with high initial Coulombic efficiency by modulated trifunctional binder for high-areal-capacity lithium-ion batteries," Advanced Energy Materials, vol. 10, no. 20, p. 1903110, 2020.

[6] L. Hencz, H. Chen, H. Y. Ling et al., "Housing sulfur in polymer composite frameworks for Li-S batteries," Nano-Micro Letters, vol. 11, no. 1, 2019.

[7] G. Li, C. Wang, W. Cai, Z. Lin, Z. Li, and S. Zhang, "The dual actions of modified polybenzimidazole in taming the polysulfide shuttle for long-life lithium-sulfur batteries," NPG Asia Materials, vol. 8, no. 10, article e317, 2016.

[8] H. Xiang, J. Chen, Z. Li, and H. Wang, "An inorganic membrane as a separator for lithium-ion battery," Journal of Power Sources, vol. 196, no. 20, pp. 8651-8655, 2011.

[9] C. Wang, W. Chen, D. Yuan et al., “Tailoring the nanostructure and electronic configuration of metal phosphides for efficient electrocatalytic oxygen evolution reactions," Nano Energy, vol. 69, p. 104453, 2020.

[10] Z. Yuan, H. J. Peng, T. Z. Hou et al., "Powering lithiumsulfur battery performance by propelling polysulfide redox at sulfiphilic hosts," Nano Letters, vol. 16, no. 1, pp. 519527, 2015.

[11] Z. Du, X. Chen, W. Hu et al., "Cobalt in nitrogen-doped graphene as single-atom catalyst for high-sulfur content lithium-sulfur batteries," Journal of the American Chemical Society, vol. 141, no. 9, pp. 3977-3985, 2019.

[12] H. Ye, J. Sun, S. Zhang et al., "Stepwise electrocatalysis as a strategy against polysulfide shuttling in Li-S batteries," ACS Nano, vol. 13, no. 12, pp. 14208-14216, 2019.

[13] L. Ma, W. Zhang, L. Wang et al., "Strong capillarity, chemisorption and electrocatalytic capability of crisscrossed nanostraws enabled flexible, high-rate and long-cycling lithium-sulfur batteries," ACS Nano, vol. 12, no. 5, pp. 4868-4876, 2018.

[14] L. Ma, R. Chen, G. Zhu et al., "Cerium oxide nanocrystal embedded bimodal micromesoporous nitrogen-rich carbon nanospheres as effective sulfur host for lithium-sulfur batteries," ACS Nano, vol. 11, no. 7, pp. 7274-7283, 2017.

[15] L. Ma, H. Yuan, W. Zhang et al., "Porous-shell vanadium nitride nanobubbles with ultrahigh areal sulfur loading for high-capacity and long-life lithium-sulfur batteries," Nano Letters, vol. 17, no. 12, pp. 7839-7846, 2017.

[16] C. Zheng, S. Niu, W. Lv et al., "Propelling polysulfides transformation for high-rate and long-life lithium- sulfur batteries," Nano Energy, vol. 33, pp. 306-312, 2017.

[17] Q. Zhang, Y. Wang, Z. W. Seh, Z. Fu, R. Zhang, and Y. Cui, "Understanding the anchoring effect of two-dimensional layered materials for lithium-sulfur batteries," Nano Letters, vol. 15, no. 6, pp. 3780-3786, 2015.

[18] B.-. W. Zhang, T. Sheng, Y.-. X. Wang et al., "Long-life roomtemperature sodium-sulfur batteries by virtue oftransition metal nanocluster-sulfur interactions," Angewandte Chemie, vol. 131, no. 5, pp. 1498-1502, 2018.

[19] Y. Zhu, T. Cao, C. Cao et al., "One-pot pyrolysis to N-doped graphene with high-density Pt single atomic sites as heterogeneous catalyst for alkene hydrosilylation," ACS Catalysis, vol. 8, no. 11, pp. 10004-10011, 2018.

[20] H. Zhang, S. Hwang, M. Wang et al., "Single atomic iron catalysts for oxygen reduction in acidic media: particle size control and thermal activation," Journal of the American Chemical Society, vol. 139, no. 40, pp. 14143-14149, 2017.

[21] M. Sun, J. Ji, M. Hu et al., "Overwhelming the performance of single atoms with atomic clusters for platinum-catalyzed hydrogen evolution," ACS Catalysis, vol. 9, no. 9, pp. 82138223, 2019.

[22] J. Ji, Y. Zhang, L. Tang et al., "Platinum single-atom and cluster anchored on functionalized MWCNTs with ultrahigh mass efficiency for electrocatalytic hydrogen evolution," Nano Energy, vol. 63, article 103849, 2019.

[23] J. Zhang, J. Fang, J. Han, T. Yan, L. Shi, and D. Zhang, "N, P, S co-doped hollow carbon polyhedra derived from MOF-based core-shell nanocomposites for capacitive deionization," Journal of Materials Chemistry A, vol. 6, no. 31, pp. 1524515252, 2018.

[24] Y. Hou, M. Qiu, M. G. Kim et al., “Atomically dispersed nickelnitrogen-sulfur species anchored on porous carbon nanosheets for efficient water oxidation," Nature Communications, vol. 10, no. 1, pp. 1392-1399, 2019.

[25] B. Ravel and M. Newville, "ATHENA,ARTEMIS,HEPHAESTUS: data analysis for X-ray absorption spectroscopy usingIFEFFIT," Journal of Synchrotron Radiation, vol. 12, no. 4, pp. 537-541, 2005. 
[26] A. S. Peinetti, M. Mizrahi, F. G. Requejo et al., "Synthesis of nickel entities: from highly stable zerovalent nanoclusters to nanowires. Growth control and catalytic behavior," Journal of Colloid and Interface Science, vol. 516, pp. 371-378, 2018.

[27] X. Zeng, X. Gao, G. Li et al., "Conductive molybdenum carbide as the polysulfide reservoir for lithium-sulfur batteries," Journal of Materials Chemistry A, vol. 6, no. 35, pp. 1714217147, 2018.

[28] C. Bannwarth, S. Ehlert, and S. Grimme, "GFN2-xTB-an accurate and broadly parametrized self-consistent tightbinding quantum chemical method with multipole electrostatics and density-dependent dispersion contributions," Journal of Chemical Theory and Computation, vol. 15, no. 3, pp. 1652-1671, 2019.

[29] S. Grimme, C. Bannwarth, and P. Shushkov, "A robust and accurate tight-binding quantum chemical method for structures, vibrational frequencies, and noncovalent interactions of large molecular systems parametrized for all spd-block elements $(\mathrm{Z}=1-86)$," Journal of Chemical Theory and Computation, vol. 13, no. 5, pp. 1989-2009, 2017.

[30] Z. Li, J. Ji, Q. Wu et al., "A new battery process technology inspired by partially carbonized polymer binders," Nano Energy, vol. 67, p. 104234, 2020.

[31] J. Bard, L. R. Faulkner, J. Leddy, and C. G. Zoski, Electrochemical methods: fundamentals and applications, Wiley, New York, NY, USA, 1980.

[32] S. Li, Z. Li, G. Cao et al., "Sulfur-/nitrogen-rich albumen derived "self-doping" graphene for sodium-ion storage," Chemistry-A European Journal, vol. 25, no. 63, pp. 1435814363, 2019.

[33] G. Huff, DOE Global Energy Storage Database, Sandia National Lab, Albuquerque, NM, 2015.

[34] Center for Sustainable Systems, University of Michigan, U.S. grid energy storage factsheet, 2019, Pub. No. CSS15-17.

[35] B. Q. Li, L. Kong, C. X. Zhao et al., "Expediting redox kinetics of sulfur species by atomic-scale electrocatalysts in lithiumsulfur batteries," InfoMat, vol. 1, no. 4, pp. 533-541, 2019.

[36] Z. Liu, L. Zhou, Q. Ge et al., "Atomic iron catalysis of polysulfide conversion in lithium-sulfur batteries," ACS Applied Materials \& Interfaces, vol. 10, no. 23, pp. 19311-19317, 2018.

[37] J. Wang, L. Jia, J. Zhong et al., "Single-atom catalyst boosts electrochemical conversion reactions in batteries," Energy Storage Materials, vol. 18, pp. 246-252, 2019.

[38] S. Mei, C. J. Jafta, I. Lauermann et al., "Porous Ti4O7Particles with interconnected-pore structure as a high-efficiency polysulfide mediator for lithium-sulfur batteries," Advanced Functional Materials, vol. 27, no. 26, article 1701176, 2017.

[39] H. Wei, E. F. Rodriguez, A. S. Best, A. F. Hollenkamp, D. Chen, and R. A. Caruso, "Chemical bonding and physical trapping of sulfur in mesoporous Magnéli Ti4O7Microspheres for highperformance Li-S battery," Advanced Energy Materials, vol. 7, no. 4, article 1601616, 2017.

[40] T.-G. Jeong, D. S. Choi, H. Song et al., "Heterogeneous catalysis for lithium-sulfur batteries: enhanced rate performance by promoting polysulfide fragmentations," ACS Energy Letters, vol. 2, no. 2, pp. 327-333, 2017.

[41] R. Carter, L. Oakes, N. Muralidharan, A. P. Cohn, A. Douglas, and C. L. Pint, "Polysulfide anchoring mechanism revealed by atomic layer deposition of $\mathrm{V}_{2} \mathrm{O}_{5}$ and sulfur-filled carbon nanotubes for lithium-sulfur batteries," ACS Applied Materials \& Interfaces, vol. 9, no. 8, pp. 7185-7192, 2017.
[42] X. Han, Y. Xu, X. Chen et al., "Reactivation of dissolved polysulfides in Li-S batteries based on atomic layer deposition of $\mathrm{Al}_{2} \mathrm{O}_{3}$ in nanoporous carbon cloth," Nano Energy, vol. 2, no. 6, pp. 1197-1206, 2013.

[43] T. Zhou, W. Lv, J. Li et al., "Twinborn $\mathrm{TiO}_{2}-\mathrm{TiN}$ heterostructures enabling smooth trapping-diffusion-conversion of polysulfides towards ultralong life lithium-sulfur batteries," Energy \& Environmental Science, vol. 10, no. 7, pp. 16941703, 2017.

[44] H. Xu and A. Manthiram, "Hollow cobalt sulfide polyhedraenabled long-life, high areal-capacity lithium-sulfur batteries," Nano Energy, vol. 33, no. 33, pp. 124-129, 2017.

[45] D.-R. Deng, F. Xue, Y.-J. Jia et al., " $\mathrm{Co}_{4} \mathrm{~N}$ nanosheet assembled mesoporous sphere as a matrix for ultrahigh sulfur content lithium-sulfur batteries," ACS Nano, vol. 11, no. 6, pp. 60316039, 2017.

[46] J. Zhang, Y. Shi, Y. Ding, W. Zhang, and G. Yu, "In situ reactive synthesis of Polypyrrole- $\mathrm{MnO}_{2}$ Coaxial nanotubes as sulfur hosts for high-performance lithium-sulfur battery," Nano Letters, vol. 16, no. 11, pp. 7276-7281, 2016.

[47] F. Liu, Q. Xiao, H. B. Wu et al., "Regenerative polysulfidescavenging layers enabling lithium-sulfur batteries with high energy density and prolonged cycling life," ACS Nano, vol. 11, no. 3, pp. 2697-2705, 2017.

[48] Z. W. Seh, W. Li, J. J. Cha et al., "Sulphur- $\mathrm{TiO}_{2}$ yolk-shell nanoarchitecture with internal void space for long-cycle lithium-sulphur batteries," Nature Communications, vol. 4, no. 1, p. 1, 2013.

[49] K. Zhang, Z. Chen, R. Ning et al., "Single-atom coated separator for robust lithium-sulfur batteries," ACS Applied Materials \& Interfaces, vol. 11, no. 28, pp. 25147-25154, 2019.

[50] J. Wu, J. Chen, Y. Huang et al., "Cobalt atoms dispersed on hierarchical carbon nitride support as the cathode electrocatalyst for high-performance lithium-polysulfide batteries," Science Bulletin, vol. 64, no. 24, pp. 1875-1880, 2019.

[51] L. Jiao, C. Zhang, C. Geng et al., "Capture and catalytic conversion of polysulfides by in situ built $\mathrm{TiO}_{2}$-MXene heterostructures for lithium-sulfur batteries," Advanced Energy Materials, vol. 9, no. 19, article 1900219, 2019. 